\title{
Differences in Interpersonal Problems Among Bereaved vs. Non- Bereaved College Students: The Impact of Loneliness and Social Inhibition
}

Adam M. Moller

West Virginia University

Follow this and additional works at: https://researchrepository.wvu.edu/etd

\author{
Recommended Citation \\ Moller, Adam M., "Differences in Interpersonal Problems Among Bereaved vs. Non-Bereaved College \\ Students: The Impact of Loneliness and Social Inhibition" (2013). Graduate Theses, Dissertations, and \\ Problem Reports. 474. \\ https://researchrepository.wvu.edu/etd/474
}

This Dissertation is protected by copyright and/or related rights. It has been brought to you by the The Research Repository @ WVU with permission from the rights-holder(s). You are free to use this Dissertation in any way that is permitted by the copyright and related rights legislation that applies to your use. For other uses you must obtain permission from the rights-holder(s) directly, unless additional rights are indicated by a Creative Commons license in the record and/ or on the work itself. This Dissertation has been accepted for inclusion in WVU Graduate Theses, Dissertations, and Problem Reports collection by an authorized administrator of The Research Repository @ WVU.

For more information, please contact researchrepository@mail.wvu.edu. 
Differences in Interpersonal Problems Among Bereaved vs. Non-Bereaved College Students:

The Impact of Loneliness and Social Inhibition

Adam M. Moller, M.S.

\author{
Dissertation submitted to the \\ College of Human Resources and Education \\ at West Virginia University \\ in partial fulfillment of the requirements \\ for the degree of
}

Doctor of Philosophy
in
Counseling Psychology

James Bartee, Ph.D., Chair

Jeffrey Daniels, Ph.D.

Ed Jacobs, Ph.D.

Monica Leppma, Ph.D.

Lisa Hamilton, Ph.D.

Department of Counseling, Rehabilitation Counseling, and Counseling Psychology

\title{
Morgantown, West Virginia \\ 2013
}

Keywords: Interpersonal Problems; Bereavement; Adolescents; Young Adults Copyright 2013 Adam M. Moller, M.S. 


\begin{abstract}
Differences in Interpersonal Problems Among Bereaved vs. Non-Bereaved College Students:

The Impact of Loneliness and Social Inhibition
\end{abstract}

Adam M. Moller, M.S.

This study explored the differences in loneliness and social inhibition between parentally bereaved and non-bereaved college students. Participants from West Virginia and Montana State universities were recruited through flyers, newspaper advertisements, and Craigslist.com. Those who volunteered were directed to a website to complete an online survey that included basic demographic information, the UCLA Loneliness Scale, and the Socially Inhibited subscale of the Inventory of Interpersonal Problems-64. Bereavement status (bereaved vs. non-bereaved) and gender of participant (male vs. female) were the independent variables in the study. Loneliness and social inhibition were the dependent variables. A MANOVA was conducted to explore the differences in loneliness and social inhibition among the independent variables. Based on this analysis, no significant differences were found between bereaved and non-bereaved young adults, nor where there gender differences among the bereaved sample. Several supplemental analyses were conducted, including a MANCOVA, bivariate correlations, secondary MANOVA, and a discriminant analysis. Results from the discriminant analysis revealed that the stage of adolescence young adults lost their parent should be given further theoretical, empirical, and clinical attention. 


\section{Dedication}

I would like to dedicate this manuscript to my mom who died when I was 15 years old. I am blessed to have known her for such a short time and thank her for teaching me selflessness and compassion. Also, I dedicate this to my wife Danielle who encouraged and supported me to complete my doctorate. Your endless support during this long journey has not gone unnoticed. 


\section{Acknowledgments}

I would like to express my appreciation to several people integral to the completion of this dissertation. First, I would like to recognize my dissertation chair and training director, Dr. James Bartee for his endless support, compassion, and trust in me throughout the dissertation and doctoral process. I would also like to acknowledge my former supervisor and dissertation committee member Dr. Lisa Hamilton who taught me much about working with college students and also to trust myself as a therapist. Finally, I appreciate the time, input, and suggestions from my dissertation committee members, Drs. Jeffrey Daniels, Ed Jacobs, and Monica Leppma. 
Table of Contents

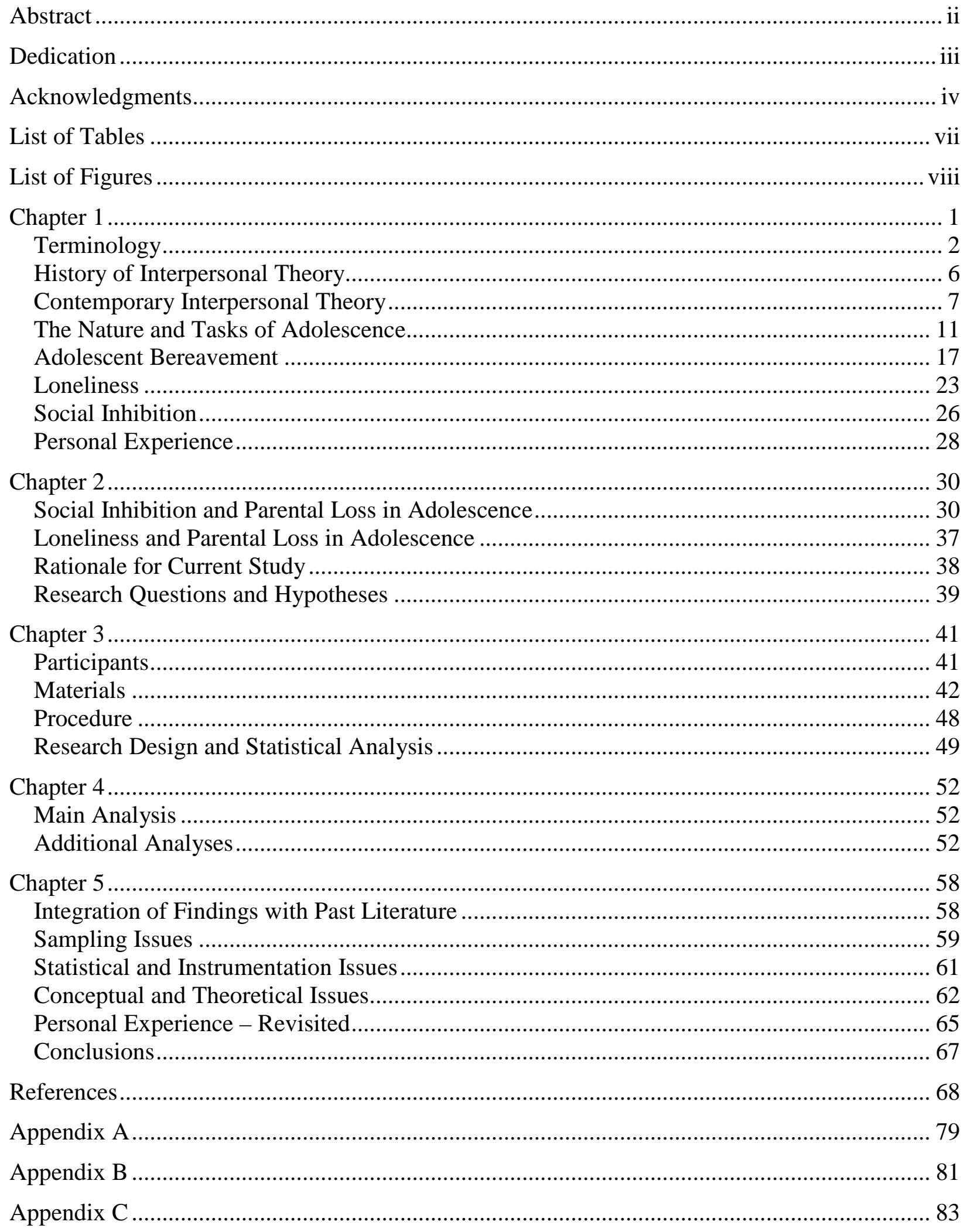




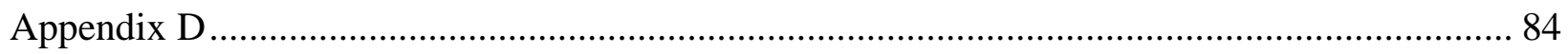




\section{List of Tables}

Table 1: Descriptive Statistics for the Total Sample ........................................................... 43

Table 2: Descriptive Statistics for Loss-Specific Variables Among the Bereaved Sample .......... 44

Table 3: Mean Loneliness and Social Inhibition Scores for Each Group ................................. 53

Table 4: Bivariate Correlations for Demographic and Dependent Variables .......................... 55

Table 5: Mean Loneliness and Social Inhibition Scores for the Bereaved Sample by Stage of

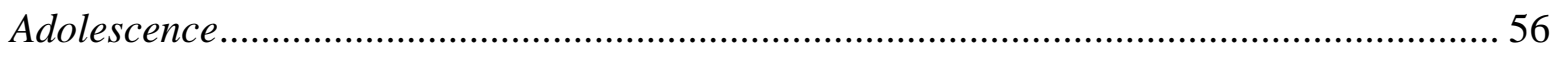


List of Figures 


\section{Chapter 1}

Researchers have found that the inability to successfully and adaptively engage in healthy relationships is associated with a variety of negative outcomes and behavior, such as divorce (Weinberger, Hofstein, \& Whitbourne, 2008), intimate partner violence (Lawson \& Brossart, 2009), and risky driving behavior (Vassallo, Smart, Sanson, Harrison, Harris, Cockfield et al., 2007). A host of psychological problems are associated with interpersonal deficits, including depression (Horowitz, Weckler, \& Doren, 1983; Youngren \& Lewinsohn, 1980), eating disorders (Hartmann, Zeeck, \& Barrett, 2010), anxiety disorders (Kleiner \& Marshall, 1987), substance abuse disorders (Doumas, Blasey, \& Mitchell, 2006), suicidal behavior (Stepp, Morse, Yaggi, Reynolds, Reed, \& Pilkoni, 2008), and personality disorders (Horowitz, Rosenberg, Baer, Ureño, \& Villaseñor, 1988; Leising, Rehbein, \& Eckardt, 2009; Ogrodniczuk, Piper, Joyce, Steinberg, \& Duggal, 2009). Moreover, interpersonal problems have been identified as one of the most common reasons people seek psychotherapeutic services (Horowitz et al., 1988). Thus, it can be asserted that interpersonal problems have a detrimental effect on the well-being of many people.

Despite the significance of interpersonal problems, their etiology seems comparatively unexplored within the relevant scientific literature. While some authors have looked at the role of negative parenting on adult love relationships (McCarthy \& Maughan, 2010), others have examined the role of significant life events, particularly traumatic experiences. Traumatic events such as sexual abuse (Kernhof, Kaufhold, \& Grabhorn, 2008; Mills \& Turnbull, 2004), military combat exposure (Zerach, Anat, Solomon, \& Heruti, 2010), and torture (Lunde \& Ortmann, 1990) have been implicated as potential sources of future interpersonal problems. Although severe trauma can impose a range of negative outcomes, such events are generally nonnormative and comparatively rare. In contrast, loss is a common occurrence and the death of a 
loved one is often one of the most challenging events in the lives of many. Thus, the purpose of this study is to reveal how losing a parent to death during one's adolescence leaves a legacy of interpersonal problems into young adulthood.

Several authors have explored how bereavement leads to interpersonal problems. However, some assessed the nature of social support and loneliness after the death of a spouse (e.g., Stroebe, Stroebe, \& Abakoumkin, 1996), while others explored intimacy levels after the death of a child (e.g., Berry, 1999). How other types of losses, such as the death of a parent, have been relatively unexplored. Furthermore, the adolescent experience of bereavement has received little attention (Fleming \& Adolph, 1986; Garber, 1985), and little is known about how adolescents are impacted by the death of a parent.

Over the past 25 years, few researchers have explored how the loss of a parent in adolescence affects subsequent interpersonal functioning among young adults (e.g., Dietrich, 1984; Hepworth, Ryder, \& Dreyer, 1984; Jacobson \& Ryder, 1969, Kippley, 1998; Maranzano, 2004; Meshot \& Leitner, 1993; Silverman, 1987). While they clarified some of the potential effects on interpersonal functioning, their studies had several methodological shortcomings. Some of the studies were limited to females (Silverman, 1987) and the death of a father (Kippley, 1998), while in other studies the psychometric properties of the instruments administered were questionable (Hepworth, 1984). Although, Meshot and Leitner (1993) explored the interpersonal styles of parentally bereaved young adults, their work did not identify specific interpersonal problems within their sample. Collectively, these researchers did not account for how the loss impacted specific developmental tasks of adolescence (e.g., Havighurst, 1972) that might contribute to future interpersonal problems.

\section{Terminology}


Interpersonal problems and social inhibition. Interpersonal problems are difficulties between two or more people that stem from frustrated interpersonal motives (Horowtiz, 2004). More specifically, they are self-reported difficulties people experience when their communion and agency needs are frustrated (Horowitz, Alden, Wiggins, \& Pinicus, 2003; Horowitz, Dryer, \& Krasnoperova, 1997). Such difficulties often consist of behaviors that fail to meet the demands of a given social situation that are often rigid, extreme, distorted, and inescapable (Kiesler, 1983; Yalom \& Leszcz, 2005). One specific interpersonal problem is social inhibition. Social inhibition is an interpersonal problem that is characterized by feelings of anxiety while interacting with other people (Horowitz et al., 2003). Individuals who are socially inhibited find it:

...hard to initiate social interactions, express feelings to other people, and socialize... [they] limit their social life and avoid activities that seem to entail personal social risks... [and] do not desire or enjoy close relationships; they almost always choose solitary activities and lack close friends or confidants. (Horowitz et al., 2003, p. 39) A chronic and persistent pattern of social inhibition is common among those with avoidant personality disorder and social phobia (Alden \& Phillips, 1990; American Psychiatric Association, 2000; Pincus \& Wiggins, 1990).

Loneliness. Loneliness is an affective state that arises from a "relational deficit" (Weiss, 1973, p. 18). Weiss (1973) indentified two kinds of loneliness emerging from relational deficiencies. The first is the loneliness of emotional isolation, which is the "absence of a close emotional attachment" (Weiss, 1973, p. 18). This sort of loneliness is not resolved by other sorts of relationships (e.g., friendships, collegial) because it can only be attenuated by forging an emotional attachment with another or recovering the lost relationship. Loneliness of social 
isolation, on the other hand, is loneliness from the "absence of an engaging social network" (Weiss, 1973, p. 19). Overcoming social loneliness depends on participating in a suitable social network. This study will explore whether parentally bereaved adolescents are at a higher risk of experiencing both kinds of loneliness.

Loss-related concepts. Worden (2009) identified three terms that are often used interchangeably with one another in the study of loss. The first is bereavement, which refers to the event of having lost someone. Grief is the experience one must endure after bereavement. Mourning, on the other hand, refers to the active process a person goes through to cope with bereavement and grief.

Adolescence. The American Psychological Association (APA) defines adolescence as, "the period of human development that starts with puberty (10-12 years of age) and ends with physiological maturity (approximately 19 years of age), although the exact age span varies across individuals" (APA, 2007, p. 21). It is a time when a variety of changes occur, including body image, sexual interest, social roles, intellectual development, and development of the selfconcept (APA, 2007).

There are other definitions that suggest different time frames for adolescence. For example, Arnett (2000) suggested that adolescence begins at the age of 10 and extends to 18 . However, some authors who study adolescent grief responses have a slightly more expansive age range of adolescence, dividing the period into three phases: (a) early adolescence, which ranges from ages 10 to 14; (b) middle adolescence, which spans approximately from ages 15 to 17; and (c) late adolescence, which extends from ages 18 to 22 (Balk \& Corr, 2001).

In this study, adolescence will be defined as 10 to 18 years old. The selection of this age range is based on the commonality among proposed definitions in the literature. For example, 
the definitions of the APA (2007), Arnett (2000), and Balk and Corr (2001) all consider adolescence to begin at approximately the age of 10 . While these definitions consider 18 to 22 years old as the end of adolescence, most are concentrated around 18 to 19 years old. Thus, 18 years appears to be an appropriate end-range age and is consistent with other authors who define this age as the start of young adulthood.

Young adulthood. Young adulthood has historically been considered the age range from 18 to 30 years old (Havighurst, 1972). This is a period of development that includes 'marker events' that indicate that adulthood is approaching (Broderick \& Blewitt, 2010). Such marker events may include marriage, pregnancy, first full-time job, and potentially buying a home, among many others (Havighurst, 1972). It is also a period when attaining interpersonal intimacy with others is a major psycho-social task (Erikson, 1959/1980). Attainment of interpersonal intimacy is not necessarily reserved for marriage or other romantic partnerships, because it can be acquired through "friendship, combat, leadership, love, and inspiration" (Erikson, 1959/1980, p. 101).

Like the span of adolescence, there are differences in the age ranges defining young adulthood. For example, Arnett (2004) set young adulthood as the period from the mid to late twenties to early thirties, while emerging adulthood refers to the span from 18 to 25 years old. Arnett $(2000,2004,2007)$ proposed qualitative differences between emerging and young adulthood. Namely, he proposed that identity formation, traditionally a focal point of adolescence (Erikson, 1959/1980; Havighurst, 1972), does not resolve by age 18. Rather, identity formation persists into the mid to late twenties (Arnett, 2000, 2004, 2007).

In this study, young adulthood refers to the years from 18 to 30 (Broderick \& Blewitt, 2010; Havighurst, 1972). While acknowledging the contributions of Arnett (2000, 2004, 2007), 
this age range captures the rich theoretical and historical contributions of Erikson (1959/1980). Given the lasting impact of Erikson's model on the field (Gelso \& Fretz, 2001), his conceptualization of interpersonal intimacy as the psycho-social challenge of young adulthood will help inform and guide the questions posed in this study.

\section{History of Interpersonal Theory}

Interpersonal theory originated from the works of Karen Horney (1945) and Harry Stack Sullivan (1953) in response to two prominent psychological models of the time, behaviorism and psychoanalysis (Horowitz, 2004). These authors were dissatisfied with the psychoanalytic and behavioral emphasis on unconscious sexual and aggressive impulses, or a series of negatively reinforcing pairings, as the causes of psychological problems. In contrast, the fundamental belief of interpersonal theorists is that psychological problems result from maladaptive social interactions (Horowitz, 2004). With that said, the ideas posited by the early pioneers of interpersonal theory deserve exploration.

Karen Horney. According to Karen Horney (1945), disturbances in human relationships stem from contradictory attitudes toward others. The contradictory attitudes arise during childhood in response to unfavorable environmental conditions. As children attempt to cope with their adverse environments, they develop "lasting character trends which become part of his [their] personality" (Horney, 1945, p. 42). Horney (1945) identified three character trends: (a) those that move toward people (the compliant personality), (b) those that move against people (the aggressive personality), (c) those that move away from people (i.e., the detached personality). People who move toward others are likely to be passive and subordinate, and their needs center on human intimacy and belonging. People who move against others feel the world is hostile, and they value strength and aggressiveness as means to get their needs met. Those 
who move away from people desire to be self-sufficient and they withdraw emotionally from others. While all three trends can be observed in healthy individuals, those who rigidly adhere to one trend likely have persistent interpersonal difficulties. Over time, this not only disrupts relationships, but it also leads individuals to ignore their own feelings and behave in ways that are not appropriate for the situation (Horney, 1945).

Harry Stack Sullivan. Harry Stack Sullivan (1953) placed tension and needs at the crux of interpersonal interactions and problems. Sullivan postulated that infants experience tension when their needs are not met (e.g., security, tenderness, physical, emotional, intellectual, etc.). He referred to this as the tension of needs. Such tension creates reciprocal tension in the caregiver who reacts with complementary behavior to decrease the infant's distress. The original tension stemming from the infant is designed to bring the infant and the caregiver together in ways that satisfy both parties. Thus, the need gives rise to tension, and the tension promotes behavior that gives rise to satisfaction of the need. This interaction is not limited to the experience of an infant; instead it persists throughout life as means of evoking reciprocal and satisfying interactions. However, when an infant's needs are not satisfied, it gives rise to anxiety and promotes the use of security operations (i.e., defenses) designed to reduce the distress. While security operations bring temporary relief, they can lead to long-term interpersonal problems with others if they are consistently relied upon.

\section{Contemporary Interpersonal Theory}

Since the works of Horney (1945) and Sullivan (1953), several authors have explored the diverse facets of interpersonal behavior and attempted to operationalize them. For example, Leary (1957) proposed that all interpersonal behavior is a function of two primary interpersonal needs or motives, communion and agency, and that such behavior arising from these needs can 
be located on a circular two-dimensional coordinate system referred to as a circumplex. Bakan (1966) developed a similar hypothesis when he noted that the need for communion and agency are the basic driving force behind all adaptive and maladaptive human behavior. Furthermore, Wiggins (1979) and Kielser (1983) developed taxonomies of interpersonal traits and behavior. However, over the past 30 years, the works of Leonard Horowitz provide the most complete synthesis and expansion of interpersonal theory across empirical (Horowitz \& Vitkus, 1986), instrumental (Horowitz et al., 2003; Horowitz et al., 1988), and clinical domains (Horowitz, 2004). Thus, the model proposed by Horowitz (2004) and his associates will be the primary interpersonal theory guiding this study.

Interpersonal needs. Interpersonal behavior is the function of two motives, the needs for communion and agency ${ }^{1}$ (Blatt, 1990; Horowtiz, 2004). Communion motives are those that encourage people to form intimate and selfless relationships with others, while agency motives are those that promote autonomy, a competent self-image, and one's performance as an individual entity (Bakan, 1966; Blatt, 1990). These needs are reciprocally shaped in tandem through developmental experiences with caregivers (Horowitz, 2004). For example, consider a young child who through the need for communion, has learned that caregivers can be trusted to provide care and protection. Once this trust is established, the child can then feel confident to meet the needs for agency by exploring the world without caregiver supervision, confident the caregivers will bring safety if it is needed. Likewise, children are likely to form intimate relationships when they become adults if they feel competent about their agency (Horowitz, 2004).

\footnotetext{
${ }^{1}$ Leary (1957) originally termed the needs dominance and affiliation, but Bakan (1966) referred to them as agency and communion. To be consistent with Horowitz (2004) and Horowitz et al. (2003), the latter descriptors will be used in this paper.
} 
Interpersonal complementarity and problems. A person's communal and agency needs promote interpersonal behavior that invites others to respond in ways that will either satisfy or frustrate the person's needs (Blatt, 1990; Horowtiz, 2004; Horowitz \& Vitkus, 1986). Expanding on the ideas of Sullivan (1953), Horowitz (2004) and others (Kiesler, 1983; Leary, 1957) have emphasized that the purpose of interpersonal behavior is to invite complementary responses by others.

The type of complementary response depends upon the motive (Horowitz, 2004). Complementary interpersonal behavior tends to be similar when the initiating interpersonal behavior stems from one's communal needs. For example, a communal behavior that seeks connection with others is likely to receive connection from others, and isolative behavior is likely to invite behavior from others that perpetuates the isolation. In contrast, complementary interpersonal behavior usually evokes opposite action when it stems from agency needs. For instance, agency motivated behavior that seeks control of others is likely to invite submissive behavior in others, and submissive behavior is likely to evoke controlling behavior. Behaviors that are non-complementary are likely to result in a power struggle (Horowitz, 2004).

Regardless of the type of complementary behavior, any interpersonal interaction that results in frustration of either person's communion or agency needs is likely to produce interpersonal problems (Horowitz et al., 1997).

Interpersonal interactions and self-concept. In addition to complementary behavior, a person's self-concept affects interpersonal interactions and problems (Horowitz, 2004). According to Horowitz (2004), one's self-concept is “... a theory of the self...the person seeks to confirm certain features and refute others" (p. 81). Like interpersonal motives, this theory of self develops in the context of relationships with caregivers (e.g., Sullivan, 1953). Through 
important empathic experiences with caregivers, the child learns important aspects of the self, such as labels for affective states and experiences as well as confirming vigor, greatness, selfworth, and perfection. For example, children who have received such experiences might think of themselves as loveable and worthy of others' intimacy. In such cases, they would seek out interactions with others that confirm these beliefs. In contrast, less adaptive experiences or persistent frustration of a child's communion and agency needs by the caregiver may lead to an unstable sense of self or feelings of being unlovable. As a result, the child might be reluctant to engage in relationships with others, which could lead to isolation. Thus, a child develops a selfimage that guides future interpersonal interactions through countless experiences of having vital needs satisfied or frustrated.

Revision of the self-concept: Death of parent. While early experiences with caregivers can have a lifelong impact on the development of the emerging self-concept, it remains a “dynamic organization that changes with experience" (Epstein, 1973, p. 407) and is constantly revised (Horowtiz, 2004). One experience that may cause a revision of the self-concept is the death of a parent during one's adolescence. Adolescents who have developed positive selfconcepts - ones that confirm that they are loveable and worthy of the company and relationship of others-are likely to seek out people and relationships that confirm this self-concept. This healthy and adaptive self-image is the function of numerous experiences with caregivers. However, what would happen if one of the caregivers died? Would the adolescent's self-image remain steadfast in the face of losing an attachment figure, or would the self-image change? If the self-image did reconstitute itself, would it be in the direction of interpersonal growth or toward interpersonal problems? 
With those questions in mind, there is evidence to suggest that when an adolescent's parent dies, the self-concept changes in maladaptive ways that prevent the formation of healthy interpersonal relationships with peers (Fleming \& Adolph, 1987; Worden, 1996). A negatively revised self-concept may also affect cognitive changes (Elkind, 1981), the tasks of adolescence (Havighurst, 1972), and the formation of a psychosocial identity (Erikson, 1959/1980). Thus, the view to be presented in this study is that the loss of a parent in adolescence will interact with these developmental aspects of adolescence, modifying the young person's self-concept in such a way that predictable interpersonal problems will develop. Such problems are hypothesized to persist from adolescence into young adulthood as well.

\section{The Nature and Tasks of Adolescence}

Adolescence is a period of instability and fluctuation (Hall, 1904). Since the early part of the twentieth century, the term "storm and stress" (Hall, 1904, Vol. 1, p. xiii) has been used to describe the drastic developmental shifts that occur in this period of the lifespan. As a result of rapid biological, emotional, and cognitive changes, adolescents experience a psychological rebirth and individuation process similar to that of infancy (Blos, 1967; Hall, 1904). Adolescents must master newly acquired physical abilities (Broderick \& Blewitt, 2010; Hall, 1904; Reiter \& Grumbach, 1982) and learn how to cope with intense fluctuation of affect (Arnett, 1999; BrooksGunn, Graber, \& Paikoff, 1994; Buchanan, Eccles, \& Becker, 1992; Hall, 1904).

Simultaneously, young people must cope with the cognitive changes, developmental tasks, and identity formation.

\footnotetext{
${ }^{2}$ The origins of this term can be traced to the 1776 play titled Sturm und Drang by Friedrich Maximilian Klinger (1752-1831). The play was intended to capture the intense and varying emotions experienced by those during the American Revolution (Wikipedia, 2012).
} 
Cognitive changes. In the midst of storm and stress, adolescents are on a "conquest of thought" (Elkind, 1981, p. 90). In early adolescence, formal operational thought is beginning to emerge and the adolescent is able to focus on the relationships among multiple objects (Inhelder \& Piaget, 1955/1958). Additionally, adolescents begin to construct ideals of the world that best match their current worldviews and they also become introspective and think critically about themselves (Elkind, 1981).

This is also a time of enhanced egocentrism (Elkind, 1981). As adolescents focus their thoughts inward, they create a distorted perception that others are constantly watching them in the form of an imaginary audience (Elkind, 1967). The notion of an imaginary audience explains a variety of adolescent behaviors, including self-consciousness and self-admiration (Elkind, 1981). This self-focused perception also explains the tendency of adolescents to believe their experiences, concerns, and feelings are special, and that they are living a personal fable in which the adolescent feels as if he or she is living in a story featuring himself or herself as the invulnerable hero.

Egocentrism, the imaginary audience, and the personal fable tend to diminish around the age of 16 as adolescents begin to relate intimately with friends and romantic partners (Elkind, 1981). As a result of enhanced interpersonal contact, egocentric adolescents begin to see themselves more realistically since they replace the imaginary audience with a real one and establish true rather than fabled interpersonal relationships (Elkind, 1981). Thus, through these relationships, adolescents become aware of the distinctions between their thoughts and those of others, and integrate their personal feelings with those of others (Elkind, 1981).

Tasks of adolescence. In the midst of these changes, the adolescent must negotiate various developmental tasks. Some authors give greater emphasis to some tasks than do others. 
For example, Elkind (1967; 1981) emphasized the cognitive challenges faced by adolescents, while Erikson (1959/1980) stressed the fundamental importance of establishing a psychosocial identity. Havighurst (1972) identified eight social and emotional tasks that adolescents must negotiate in order to experience psychological growth. His model is more nuanced than Erikson's as it breaks down this stage of development into multiple sub-tasks that lead to the development of one's identity. Because of the added complexity and sophistication of Havighurst's model, I will be using it in this study to help explain the impact of losing a parent in adolescence.

Havighurst's (1972) tasks are rooted in the physical maturation of the adolescent, cultural demands of society, and the adolescent's personal values and aspirations. Havighurst's eight tasks of adolescence are: (a) achieving new and more mature relations with age-mates of both sexes, (b) achieving a masculine or feminine social role, (c) accepting one's physique and using the body effectively, (d) achieving emotional independence of parents and other adults, (e) preparing for marriage and family life, (f) preparing for an economic career, $(\mathrm{g})$ acquiring a set of values and an ethical system as a guide to behavior-developing an ideology, and (h) desiring and achieving socially responsible behavior.

Many of these tasks have relationships with others at their center. Tasks 1, 4, and 5 all require that the adolescent develop relationships with others for adaptive social adjustment across the lifespan (Havighurst, 1972). As a result, failure to attain any one of these tasks may prevent one from successfully engaging in healthy relationships and lead to future interpersonal problems. For example, an inability to achieve mature relationships with peers in adolescence (Task 1) tends to be associated with difficulties later in marriage and work (Havighurst, 1972). Likewise, a failure to emotionally separate from one's parents (Task 4) often leads to emotional 
dependence upon them into adulthood and the inability to develop and maintain age-appropriate adult relationships (Havighurst, 1972).

Relationships with peers not only contribute to the cognitive maturation of the adolescent, they are also crucial to the fulfillment of many of the tasks of adolescence. Taken collectively, the achievement of these relationship-oriented tasks and the social context for which they are resolved lend to the constitution of one's identity (Havighurst, 1972). Furthermore, if a given task is not achieved at the proper time it will not be achieved well. Failure in this task will cause partial or complete failure in the achievement of other tasks yet to come (Havighurst, 1950), which is a feature common to all stage theories of development.

Identity development. In order to understand identity development, it would be helpful to begin with Erickson's (1959/1980) psychosocial theory of development as psychologists continue to regard it as one of the most prominent theoretical models for understanding normal development across the lifespan (Gelso \& Fretz, 2001). According to Erikson, personality, identity, and ultimately mental health develop according to a series of stages where the individual approaches and interacts with a wide array of social contacts. Erikson proposed that this emergence of self occurs in eight stages from birth to the end of life: (a) trust versus mistrust, (b) autonomy versus shame and doubt, (c) initiative versus guilt, (d) industry versus inferiority, (e) identity versus identity diffusion, (f) intimacy versus isolation, (g) generativity versus self-absorption, and (h) integrity versus disgust and despair.

Adolescents and young adults are usually in stages five and six of Erikson's (1959/1980) model. During adolescence, individuals actively explore the possibilities in love, work, and worldviews. This eventually leads to lasting commitments in each of these areas and contributes to the individual's identity toward the end of the teenage years (Stage 5). Commitments in these 
areas are usually made in ways that preserve and maintain one's "inner sameness and continuity" (Erikson, 1959/1980, p. 94) over time, and are congruent with the individual's self-concept. An inability to settle on such commitments results in a diffused identity state, which prevents the individual from successfully navigating the next psychosocial stage involving intimacy versus isolation (Stage 6). Thus, the individual with an unsure identity "shies away from interpersonal intimacy... and comes to retain a deep sense of isolation" (Erikson, 1968, pp. 135-136). In other words, those whose identity formation is disrupted or unresolved may experience interpersonal problems in young adulthood. There are other theorists, besides Erikson, whose ideas about the formation of identity are relevant to this study.

Melanie Klein. Melanie Klein (1935) postulated that a child's interactions with caregivers helps the child organize experiences and to foster different versions of self in relation to others. Through early interactions with caregivers, the child develops models of the self and others that are "good" (loved and loving) or "bad" (hateful and destructive). As the child's relationship with the caregiver deepens, the child realizes that both good and bad features exist in others, which creates anxiety because of its ambiguous nature. It is the normal feeling humans experience when they try to integrate and tolerate complex and seemingly incongruent feelings and thoughts toward objects and relationships. However, individuals often regress to more dichotomous ways of thinking about relationships to avoid distressing emotions caused by experiences such as loss, rejection, and frustration.

Margaret Mahler. Margaret Mahler (1974) also placed emphasis on the early relationship between a caregiver and child in the formation of an identity. Mahler believed that identity is formed in early years of life through a process called separation-individuation. The thrust of her theory is that young children wax and wane in their perceptive abilities and desires 
to be autonomous or dependent upon their caregivers. As long as the caregiver remains emotionally available, the child learns to cope with the world as a separate individual. However, Mahler noted that if the caregiver is unavailable or if there are other disturbances in this separation-individuation process, "narcissistic character formation and/or borderline pathology" (1974, p. 103) might develop instead of a healthy identity.

Heinz Kohut. Heinz Kohut (1977) theorized that the development of healthy narcissism (e.g., one's self-worth and self-esteem) is dependent on a child's self-object experiences with caregivers. Kohut and Wolf (1978) identified three types of self-object experiences a child must have for healthy narcissism to develop and flourish. A caregiver must respond to and mirror the child's greatness, self-worth, and accomplishments—an experience called mirroring. The caregiver must also provide a model of calmness and resilience so the child can internalize these characteristics. This experience is called idealizing. Finally, twinship experiences arise from the caregiver evoking a sense of similarity between the child and the caregiver, which provides the child with a sense of connection and security. Any deficient self-object experience arising from an absent, inconsistent, or deceased caregiver is likely to result in unhealthy narcissism, depression, and identity confusion because the child's sense of self has not been validated or confirmed.

Thus it can be seen that adolescence is a volatile and complex period of the lifespan. Adolescents must learn to endure, cope with, and adapt to the rapid biological, cognitive, emotional, and social changes they experience. This involves learning to resolve egocentrism, negotiate the tasks of adolescence, and forge an identity — all of which have relationships with other people as their focal point. 
Early developmental experiences could also influence these tasks of adolescence and the development of the self-concept. Erickson (1959/1980) noted that the development of a healthy identity at a particular point in the lifespan depends on successfully negotiating earlier stages of development. Consequently, individuals who are unable to establish the needed identity during adolescence are likely to have difficulty attaining intimacy in young adulthood. Likewise, an infant who is unable to resolve the first stage of identity development (trust versus mistrust) is likely have difficulty adapting to the second stage of autonomy versus shame and doubt. Children who lack a clear sense of autonomy often cope by over-controlling their behavior. As Erikson (1959/1980) put it, this "is the model for compulsive neurosis...the classical compulsive character...[the person] goes through life habitually ashamed, apologetic, and afraid to be seen" (p. 73). With this example in mind, the child whose needs for trust or autonomy have not been met (or other psychosocial components of one's identity) may find the tasks of adolescence more demanding. Additionally, such early developmental experiences are likely to affect the child's developing self-concept (Horowitz, 2004), especially if a parent dies. Before describing how this occurs, an explanation of how adolescent bereavement intersects with adolescent development is needed.

\section{Adolescent Bereavement}

John Bowlby's $(1969,1973,1980)$ attachment theory is the cornerstone of understanding bereavement and loss. His theory is so important that, “...no serious student of bereavement or of child development can afford to ignore this major work, whose influence continues today" (Parkes, 2001, p. 37). Before discussing how Bowlby's attachment theory is applicable to death of a loved one, it is useful to provide a brief overview of his general attachment theory to highlight the importance of early relationships to one's physical and psychological health. 
Overview of Bowlby's attachment theory. Bowlby theorized that the primary task of an infant (will be referred to as a child) is to develop an attachment to a caregiver (Bowlby, 1969). The development of this attachment is attained through a series of phases whose aim is to differentiate the caregiver from other humans. At first, the child is limited to olfactory and auditory means to recognize the caregiver. It is not until six to eight months of age that the child displays marked discrimination between the caregiver and others. The child will pleasantly greet the caregiver, but tends to be wary and cautious of strangers.

When separated from the caregiver the child will cry, call, and perform other tantrum-like behaviors in an attempt regain a safe proximity to the caregiver (Bowlby, 1973, 1980). If this behavior is unsuccessful, the child will experience despair but will attentively wait for the caregiver to return. If the caregiver does not return, the child begins to emotionally detach from the caregiver. This detachment is not long lasting because separations are temporary. However, when the child senses that the caregiver will leave again the child experiences separation anxiety.

How a child reacts during periods of separation from the caregiver tends to predict adult attachment relationships. Bowlby (1980) recognized parallels between a child's attachment to a caregiver and the attachments that occur between two adults. The same behavior that an individual displayed when forming and maintaining the child-parent attachment is theorized to be stable across the lifespan and permeate adult-adult attachments.

Phases of mourning. When a child, adolescent, or adult loses a loved one, they move through four phases of mourning (Bowlby, 1980) that parallel the behavior of a child who has been separated from the caregiver (see Bowlby, 1969, 1973). The first phase is numbing, which usually occurs hours to a week after the loss. This stage is characterized by shock, anger, and other outbursts of strong emotion. The next phase, yearning, lasts from months to years after the 
event. Yearning behavior includes a search for the lost loved one. This search may be cognitive (e.g., intense thinking of the lost person) or physical, such as calling or crying out for the lost person. The bereaved may misinterpret sensory information to indicate that the deceased is alive, such as interpreting the sound of a car as the deceased returning home from work. In the third phase, disorganization, the bereaved finds the yearning behavior to be ineffective, and realizes it is not going to bring the deceased attachment figure back into proximity as it did during brief separations during childhood. Depression and apathy often set in after one comes to this awareness.

In the final stage, reorganization, bereaved individuals accept that they must relearn the world and renegotiate a self without the lost person. For example, in response to a male partner losing his spouse, Bowlby (1980) stated, "No longer is he a husband but a widower. No longer is he one of a pair with complementary roles but a singleton. This redefinition of self and situation is as painful as it is crucial..." (p. 94). Redefining the self and the situation eventually leads to a withdrawal of emotional investment in the lost person in order to prepare for a relationship with another. In addition to Bowlby, there are other authors whose work pertains to this study.

Elisabeth Kübler-Ross. Perhaps the most influential thanatologist was Elisabeth Kübler-Ross (1969) who described how terminally ill patients cope with the news of their impending death. Kübler-Ross summarized the responses of over 200 interviews with dying patients into a five-stage model: (a) denial and isolation, (b) anger, (c) bargaining, (d) depression, and (e) acceptance. According to Kübler-Ross, dying individuals cope with their mortality by starting at the first stage (denial and isolation) and progress linearly through the model to the final stage (acceptance). This model has been the cornerstone for professional caregivers as a 
way to conceptualize the experience of their patients (Corr, 1993). Unfortunately, wellintentioned mental health clinicians have often applied this model to the experience of the bereaved when it was intended to describe the experience of dying patients. It is understandable why the model would be applied to both dying and bereaved people as both populations are faced with loss and are in mourning. However, applying the model to the experience of bereaved individuals seems to oversimplify their experience and can place demands on them for what stage of grief they should be in. Regardless of how the model is applied, Kübler-Ross seemed to have an appreciation for the effects of parental loss in adolescence, noting, “... adolescence is in itself a difficult time and added loss of a parent is often too much for such a youngster to endure" (Kübler-Ross, 1969, p. 185).

Intersection between bereavement and development. While Bowlby's (1980) model is applicable to the adolescent grieving process, it does not describe the phenomena associated with the loss of a parent in adolescence. Bowlby's model overlooks many of the developmental changes and tasks unique to adolescence noted above. Those developmental tasks and changes are so important, that prominent bereavement scholars who have tried to conceptualize the effects of loss during adolescence have stated, "Loss in adolescence cannot be fully understood unless it is placed within the context of normal developmental tasks and stages" (Balk \& Corr, 2001, p. 199).

According to Sugar (1968), normal adolescent development is analogous to the mourning process. Sugar adapted Bowlby's phases of mourning to arrive at a three-phase model that described normal adolescent development, which includes the separation-protest phase, the disorganization phase, and the reorganization phase. During the early years of adolescence, individuals exercise a healthy need to remove themselves from their parents so they can 
eventually become independent and mature adults. Sugar refers to this individuation process as "object removal," which signifies the first phase of normal adolescent development, the separation-protest phase. Akin to Bowlby's (1980) first phase of mourning, the adolescent will display anger and other strong emotions in an attempt to regain protection from the parent once more. Maladaptive behavior may also be present. For example, truancy, stealing, or skipping school often occur as attempts to avoid the painful feelings of separating from parents. The disorganization phase begins when the adolescent realizes that protests are futile. Some adolescents then feel inadequate, worthless, and empty, and they may cope with these strong emotions through impulsive and antisocial behavior. Such behaviors offer hope that they can be reunited with their previously protective parents. Thus, the mood shifts characteristic of adolescence typifies this phase. The last phase of normal adolescent development is the reorganization phase. This is a phase of budding maturity, typically between the ages of 17 and 25 , when the adolescent is relatively calm, but may include some regression toward the disorganized phase.

Other authors have proposed a specific model that details how adolescent development is impacted by bereavement. In the model proposed by Fleming and Adolph (1986), adolescence consists of three phases ranging from age 11 to 21 . Each phase is characterized by a specific conflict that causes distress. From the ages of 11 to 14, adolescents must resolve the separation versus reunion conflict by becoming emotionally separate from their parents. Independence versus dependence is the second phase of adolescence, which ranges from age 14 to 17. Adolescents in this phase look to fortify their competence and achieve mastery and control over their lives. Finally, in late adolescence (age 17 to 21 ) the conflict consists of closeness versus distance. In this third phase, the adolescent struggles with issues surrounding intimacy and 
belonging. In all three phases adolescents must work toward resolving five core issues:

predictability of events, self-concept, belonging, fairness and justice, and mastery and control. Progress toward the resolution of these issues can be evidenced by cognitive, behavioral, and affective responses.

Fleming and Adolph (1986) contend that bereaved and non-bereaved adolescents have different cognitive, behavioral, and affective responses to each core issue across all three phases of adolescence. For example, consider the cognitive responses to the core issue of self-concept for two individuals in the third phase of adolescence. At this phase, both adolescents would be coping with their self-concepts within the context of the closeness versus distance conflict. A cognitive response of the non-bereaved adolescent to this dilemma may include "I want to and I can trust others to give me comfort and solace when I am vulnerable" (Fleming \& Adolph, 1986, p. 109). However, parentally bereaved adolescents may be hesitant to trust others after these events. They are likely to feel that few people understand them, and fear that if they get close to others those people may also die (Silverman, 1987). A typical behavioral response of such an adolescent is to isolate and withdraw from others (Fleming \& Adolph, 1986).

As one can see, the overlap between normal adolescent development and mourning caused by the death of a parent may not be easily demarcated (Fleming \& Adolph, 1986; Garber, 1985). During adolescence, these young people are already trying to negotiate normal developmental challenges (Elkind, 1981; Erikson, 1959/1980; Havighurst, 1972), which can resemble mourning (Sugar, 1968). The loss of a parent complicates this developmental process. Thus, bereavement in adolescence may "interfere with the natural progression of intellectualemotional-psychological 'growing up'...may put the adolescent 'on hold' in one phase [of adolescence], and thus inhibit the energy and skills necessary to meet subsequent phase- 
appropriate demands" (Fleming \& Adolph, 1986, p. 101-102). In other words, the loss changes the self-concept of the adolescent and leaves a legacy of interpersonal problems spanning the remainder of adolescence and into young adulthood.

When an adolescent loses a parent, the self-concept is filled with thoughts of being "marked" (Fleming \& Adolph, 1986, p. 109) and the "odd kid" (Worden, 1996, p. 90). The behavioral and affective consequences of such cognitions are isolation and loneliness (Fleming \& Adolph, 1986). Isolative behavior would have maladaptive effects on the adolescent's psychological development. Withdrawing from others would stymie the adolescent's ability to achieve mature relationships with peers and transfer the emotional bond from parents to peers (Blos, 1967; Havighurst, 1972). It would also limit the chances of developing an appropriate egocentric cognitive system (Elkind, 1981) and prevent the self-concept from overcoming thoughts of being marked or the odd kid. Finally, the adolescent would be unlikely to explore other relational aspects of identity formation such as love, which would have impacts for achieving intimacy and avoiding loneliness in young adulthood (Erikson, 1968). Thus, the cumulative effect of this self-concept and isolation is that the individual misses out on important developmental experiences that lead to healthy and adaptive relationships with others. The inability to form healthy relationships in adolescence is likely to persist into young adulthood. Without these relationships, the young adult would likely experience pervasive loneliness and interpersonal problems, such as social inhibition (Horowitz et al., 2003).

\section{Loneliness}

In his seminal work on the subject, Weiss (1973) noted that loneliness originates from a "relational deficit" (Weiss, 1973, p. 18). He believed that loneliness stemmed from either emotional or social isolation, or in some cases, both. Collectively, loneliness arising from both 
emotional and social isolation gives rise to depression and non-specific dissatisfaction with one's life. However, there are unique facets of each form of isolation that promote different symptoms and resolutions.

Loneliness from emotional isolation is closely linked with the loss of any close attachment figure by death, divorce, or abandonment. With time, what starts out as a longing for the specific lost person becomes “objectless pining” for another close attachment (Weiss, 1973, p. 92). Obtaining a new emotional attachment or finding the lost person is the only way to alleviate this form of loneliness. Other sorts of relationships such as friendships or collegial ties will not suffice. Anxiety and chronic emptiness are prominent symptoms of emotional isolation.

Loneliness from social isolation stems from insufficient social contact with peers, community, and a social network (Weiss, 1973). The socially lonely person is not seeking a specific relationship, but rather acceptance by a peer group. Such loneliness can only be alleviated by access and immersion into such a social network. A close emotional attachment with another will not reduce the distress. In contrast to emotional isolation, loneliness from social isolation is unique in that it is experienced as boredom and "feelings of exclusion" (Weiss, 1973, p. 148) or being "left out" (Weiss, 1973, p. 146).

Many lonely individuals, regardless of whether it stems from emotional or social isolation, keep their despair to themselves (Weiss, 1973). Such individuals would rather endure such distress than risk humiliation by talking about their experience. Consequently, they accept "the impossibility of bridging the gulf between themselves and others" (Weiss, 1973, p. 192). Over time, the lonely begin to physically and emotionally withdraw from others (Weiss, 1973) and typically feel different, unloved, and inferior (Horowitz, French, \& Anderson, 1982). 
Loneliness and loss. Adolescents who lose a parent are likely to experience loneliness from both emotional and social isolation. As previously mentioned, loneliness from emotional isolation is likely to ensue after a loss (Weiss, 1973). Parentally bereaved adolescents have lost a primary attachment figure, and the anxiety purported to accompany emotional isolation (Weiss, 1973) appears reminiscent of separation anxiety noted by Bowlby (1973) — the adolescent is searching for the lost parent. According to Bowlby (1980), the adolescent would move through the phases of mourning, and eventually realize that the deceased parent is unable to be recovered. At this time, the adolescent would experience objectless pining for a new attachment (Weiss, 1973). This loneliness and pining would persist until the bereaved adolescent withdrew the bond from the parent ${ }^{3}$ (Bowlby, 1980) and found a new emotional attachment (Weiss, 1973).

Loneliness and isolation from the loss also extends into the bereaved adolescent's social sphere. Developmentally, adolescents are most susceptible to social isolation as acceptance and engagement with one's peers is of utmost importance (Weiss, 1973). Adolescents attempt to achieve "self-definition in part by identifying with those other adolescents with [whom they have] something in common" (Weiss, 1973, p. 147). The peer group helps to communicate perceptions of the individual, which in turn, helps the individual to sustain an identity and selfconcept (Weiss, 1973). Thus, engagement with peers is just as important as attachment in order to ward off loneliness, and deficits in peer interactions may be just as distressing as a lost attachment figure (Weiss, 1973).

Changes in bereaved adolescents' self-concept as a result of the loss also inhibit this socialization process and promote loneliness. In addition to the grief and longing for an

\footnotetext{
${ }^{3}$ A review of whether bereaved individuals completely withdraw their emotional bonds from their deceased loved ones is currently under debate and beyond the scope of this paper. Readers who wish to learn more about this topic are encouraged to consult Stroebe (1992) and Stroebe and Schut (2005).
} 
emotional attachment with another, adolescents have thoughts of being marked and out of place (Fleming \& Adolph, 1986; Worden, 1996). As a result, they withdraw from peers during a period of development when they are already susceptible to the loneliness of social isolation (Fleming \& Adolph, 1986; Weiss, 1973). Indeed, some researchers have found that bereaved adolescents were more socially withdrawn than their non-bereaved peers (Worden, 1996). While social isolation may be a secondary consequence of losing a spouse (Weiss, 1973), loneliness due to social isolation is likely a secondary consequence to the loss of a parent during adolescence. For these individuals, their communion and agency needs are frustrated (Howowitz, 2004), they are lonely from both emotional and social isolation, and they are likely to experience interpersonal problems into young adulthood.

\section{Social Inhibition}

The interpersonal problem of social inhibition originates from the Inventory of Interpersonal Problems ${ }^{4}$ (IIP; Horowitz, 1979). In brief, the IIP is a self-report measure that identifies a person's interpersonal difficulties (Horowitz et al., 2003). Horowitz (1979) first identified the construct after performing a cluster analysis on the original 127 items of the IIP. In that analysis, a 'sociability' cluster of problematic behaviors emerged among the items. Horowitz et al. (1988) then reassessed the IIP to identify six subscales among the items with one of those subscales termed 'Sociable.' In a later study, Alden, Wiggins, and Pincus (1990) reconfirmed the existence of that construct among the items of the IIP by using a principal components factor analysis. Those authors found that 64 items of the original 127 loaded on eight factors forming several subscales. Among those items, a 'Socially Avoidant' subscale

\footnotetext{
${ }^{4}$ Full description of the IIP will be provided in Chapter 2.
} 
emerged. Finally, Horowitz et al. (2003) replicated the findings of Alden et al. (1990), and identified a subscale that they termed 'Socially Inhibited.'

Social inhibition is also a function of the two interpersonal motives of communion and agency, which can be represented on a two dimensional coordinate system (Alden et al., 1990; Horowitz, 2004; Horowitz, et al., 2003; Kiesler, 1983). Communion assumes the x-axis in this system, while agency assumes the $y$-axis. Both axes range from -1 to +1 . Attributes of communion such as 'connected' and 'loving' fall along the positive end of the $\mathrm{x}$-axis, while attributes such as 'disconnected' and 'distant' are plotted along the negative end of the X-axis. Attributes of agency such as 'influencing' and 'controlling' are plotted along the positive end of the y-axis, while attributes such as 'submitting' and 'yielding' are plotted along the negative end of the $y$-axis. Combinations of the $\mathrm{x}$ and $\mathrm{y}$-axes $(-1,+1)$ describe a variety of interpersonal behaviors and traits (Horowitz, 2004). When these traits are plotted on a graph, the resulting plots are circular in shape forming a circumplex. Traits that are plotted near each other on the circumplex are positively correlated and have similar meanings. Thus, those who display one trait are likely to display the other. Traits that are plotted opposite to each other on the circumplex are negatively correlated and have divergent meanings. In other words, it is unlikely that a person who is high on one trait will display another that is plotted diagonally on the circumplex. Traits that are neither close nor opposite on the circumplex are uncorrelated.

Individuals low on the communion and agency axes are said to be socially inhibited (Alden et al., 1990; Horowitz, 1979; Horowitz, 2004; Horowitz et al., 2003). Such individuals' communion and agency needs are frustrated, and they are likely to find it difficult to make connections and be assertive with others. They report difficulty socializing (Horowitz \& Vitkus, 1986) and may experience anxiety when attempting to do so (Horowitz et al., 2003). 
Specifically, this may manifest as hesitancy to initiate social activity with others, extend oneself to maintain friendships once formed, or express feelings with others (Alden et al., 1990; Horowitz, 1979). Those who are socially inhibited and lonely report that "making friends in a simple, natural way" is the most significant and prototypical problem they face (Horowitz \& French, 1979, p. 763; Horowitz et al., 1982).

Social inhibition and loss. Parentally bereaved adolescents and young adults are likely to struggle with social inhibition. Not only is social inhibition a significant correlate of loneliness (Horowitz \& French, 1979; Horowitz et al., 1982; Horowitz \& Vitkus, 1986), but there is a theoretical expectation that this interpersonal problem would exist among young adults who have lost a parent in adolescence. Due to a revised self-concept, isolative behavior, and insufficient relational experiences with others in adolescence, the bereaved adolescent's social skills for engaging and feeling confident with others is crippled. Opportunities to try out new behaviors with peers were missed, and the adolescent finds it hard to initiate social interactions, express feelings to others, join groups, and socialize in young adulthood. Consistent with the adolescent's loneliness, the needs for communion and agency needs are not met and “interpersonal competence" is often lacking (Horowitz et al., 1982, p. 185).

\section{Personal Experience}

I have personal experience with losing a parent in adolescence. When I was 15 years old, my mother died from cancer. The loss had a profound impact on my ability to relate to my peers in adolescence and in young adulthood. While my experience with that loss informed this research topic, it is not entirely consistent with the argument and research evidence presented here. Thus, I am mindful of my personal experience, but I have also striven to maintain an 
objective relationship to the theoretical and empirical evidence to support the rationale for this study. 


\section{Chapter 2}

An exhaustive literature search revealed few studies where researchers assessed social inhibition and loneliness among young adults who lost a parent in adolescence. In fact, only one researcher was found to have explored loneliness after the loss (Murphy, 1988). Social inhibition is even more problematic as not a single study was found where the authors assessed this construct among parentally bereaved young adults.

\section{Social Inhibition and Parental Loss in Adolescence}

To supplement for the lack of social inhibition research, other types of interpersonal problems will be considered. Among the interpersonal dynamics affected by the death of a parent during an individual's adolescence are trust (Jacobson \& Ryder, 1969), interpersonal functioning (Meshot \& Leitner, 1993), perceived comfort in relationships (Kippley, 1995), intimacy status (Maranzano, 2004), and overall psychological health (Dietrich, 1984; Silverman, 1987). Unfortunately, few authors have examined any of these variables more than once. Thus, these studies need more elaboration.

Jacobson and Ryder (1969) assessed the constructs of trust, anger, and interpersonal closeness among married couples ages 18 to 27 with a history of parental death prior to marriage. Ninety couples drawn from a community sample with a parental loss history and 30 control couples were administered a 7-hour assessment battery consisting of interviews and personality instruments (these protocols were not described by the authors). The time of parental death was not limited to adolescence so couples with a history of parental loss in childhood were also included in their study. Based on their analysis, Jacobson and Ryder identified four 'marriage syndromes' based on when one of the spouses had experienced the death of their parent. Those syndromes specific to adolescent loss were the 'closeness, late loss' and the 'mid-adolescent 
loss' syndromes. The former were those who lost a parent around the age of 17 and were found to be the healthiest of the married couples. The latter syndrome consisted of those who had lost a parent around the age of 16 . These couples experienced sexual problems in their marriages. While this study illuminated how parental loss can affect marriages, there are a few limitations worth noting. It is unclear which specific instruments were administered to the participants, rendering it difficult to ascertain whether the constructs were measured appropriately. Also, the time of parental death was not unique to adolescence because participants who had lost a parent in childhood were included in the study, which introduces developmental confounds from a different period of the lifespan.

Hepworth et al. (1984) examined the effects of parental loss on intimate relationships among married and non-married young adults. The authors sampled from two populations: nonmarried undergraduate college students and married couples from the community. The nonmarried sample consisted of 248 college students; 57 with recent parental death, 61 with recent parental divorce, and 132 controls with no $\operatorname{loss}^{5}$. Of the 196 married couples, 98 had a history of parent loss after the age of 16 and before marriage while the remaining 98 had not experienced parental loss. All participants were between the ages of 18 and 27 and were administered the Personal Relationship Questionnaire which was constructed for the study. Collectively across both samples, the researchers concluded that those who had experienced the death of a parent in late adolescence tended to either quickly enter into intimate relationships or avoid them all together as compared to those without a history of parental death. Overall, most of the bereaved individuals favored avoidance of intimacy. However, given the shortcomings of this study, the findings must be interpreted with caution. For example, the authors did not provide any

\footnotetext{
${ }^{5}$ The authors of this study reported that their total sample size was 248 when these numbers add up to 250 .
} 
psychometric data for the Personal Relationship Questionnaire, which calls into question the construct validity of the instrument. Additionally, it is difficult to ascertain when the undergraduate college sample experienced parental loss (authors note 'recent parental death'). It could be that the individuals in this sample lost their parents in young adulthood rather than adolescence, which would introduce developmental confounds as to why they avoided intimate relationships.

That same year, Dietrich (1984) examined the general psychological effects of parental loss and found evidence for interpersonal disruption. Ninety-six college students between the ages of 18 and 26 years comprised the sample in this study. Three groups were formed among the participants: (a) an early loss group (parental death before age 7), (b) a late loss group (parental death between age 12 and 18), and (c) a no-loss group. The Minnesota Multiphasic Personality Inventory-168 (MMPI-168) was administered to all participants. The author found that the Social Introversion and Hypochondriasis scales were significantly higher among those who had lost a parent (early and late loss) compared to the control group. However, when comparing the two loss groups, the late loss group had higher Social Introversion scale scores than the early loss group. Sex and age at time of death were not associated with elevations in this scale. These results are consistent with the rationale proposed by this study, which suggests that the loss of a parent during adolescence will hinder later social functioning. However, Dietrich's research was exploratory, and the author did not analyze the role of developmental factors in the emergence of social introversion.

In an exploratory study, Silverman (1987) investigated the effects of parental death on female college students and found that their love relationships were impacted. Eighteen undergraduate and graduate female college students who had lost a parent in the past two years 
comprised the sample (age at time of loss was not provided). Silverman conducted two-hour qualitative interviews but did not use a specific qualitative methodology to analyze the data. The loss of a parent had a detrimental impact on the lives of the young women. Most notably, the women reported that the loss of their parent made it difficult for them to establish long-term love relationships. Several women mentioned being hesitant to become too close with a man because of their fear that "something will happen to him" (Silverman, 1987, p. 401). Unfortunately, Silverman (1987) did not specify how old the participants were at the time of study (author notes 'college-age') or when they had lost their parent aside from within the 'past 2 years.' As noted, this potentially introduces developmental confounds making it difficult to ascertain why the participants would be fearful of their partners dying. Moreover, her study only includes the experience of women and it is not known whether male college students would also experience the same interpersonal difficulties.

Meshot and Leitner (1993) measured interpersonal functioning and 'death threat' among 42 college students between the ages of 18 and 27. Twenty of the participants lost a parent to death between the ages of 12 and 18 and served as the death-loss group. The remaining 22 participants who served as the control group had parents who were married and never divorced. The Interpersonal Repertory Grid and the Fundamental Interpersonal Orientation-Behavior (FIRO-B) were administered to assess death threat and interpersonal functioning, respectively. With respect to interpersonal functioning, the death-loss group scored higher on the WantedInclusion scale of the FIRO-B than the control group. The authors also noted some gender by group membership effects. Males in the death-loss group scored higher than males in the control group on the Wanted-Affection scale of the FIRO-B, whereas the females in the control group scored higher than the females in the death-loss group on that same scale. In sum, young adults 
who had lost a parent between ages 12 and 18 had a stronger desire to be included by their peers than those whose parents were still married. The males tended to seek close personal ties with everyone while the females avoided close relationships. Although this study addressed many of the factors observed in other studies (e.g., specifying current age and age at time of loss), the role of disrupted developmental tasks and stages were not proposed as reasons why some of the young adults had a strong desire to be included by their peers while others avoided close relationships.

Kippley (1998) explored the effects of parental loss and the variable 'perceived comfort in relationships.' The sample included 210 college students and 16 young adults from the community all between the ages of 18 and 21. Fifty-six of the participants had lost their fathers to death when the participants were between the ages of 8 and 18. Sixty-seven of the participants had parents who had divorced when the participants were between the ages 8 and 18. The parents of the remaining 87 participants were all alive and not divorced. Perceived comfort in relationships was one of several outcome variables in this study, and it was assessed through the Close Relationship Questionnaire. The author found no between group differences in perceived comfort in relationships among any of the three groups. However, several within group differences were identified for those whose fathers had died. Parentally bereaved young adults who had a secure attachment to their fathers prior to death and who had parental support after death had higher levels of perceived comfort in relationships. Additionally, attachment to the father and perceived social support were significant predictors of perceived comfort in relationships. While this study demonstrated how parental loss could affect perceived comfort in relationships, there are a few noteworthy limitations to the study. First, the construct validity and psychometric properties of the Close Relationship Questionnaire (as means to assess perceived 
comfort in relationships) were absent, calling into question the overall appropriateness of the instrument. Second, the sample included those who lost a parent in childhood and adolescence, which introduces developmental confounds from a different period of the lifespan. Third, the researcher sampled from college student and community populations, rendering it difficult to generalize the results to either population with much confidence. Finally, as with the previously reviewed studies, developmental factors were not considered.

Maranzano (2004) investigated the impact of parental loss on intimacy and identity statuses among young adults from community and university settings. The sample included 53 young adults who had lost parents in adolescence and 52 non-bereaved young adults who had not experienced such a loss. All participants were between the ages of 19 and 28. Using the Intimacy Status Interview, the Identity Styles Inventory, and the Extended Objective Measure of Ego Identity Status, the researcher found that bereaved young adults were more likely to have a developmentally lower intimacy status (i.e., stereotyped/psuedointimate) than their non-bereaved peers. Additionally, the age at time of death affected the intimacy status for the bereaved individuals with the older adolescents having higher intimacy status classifications. While this study offers insights into the influence of parental loss on intimacy on bereaved young adults, it is potentially limited by the overlap between university and community populations, as it is difficult to ascertain how robust the findings are for either one.

As one can see, researchers have studied a variety of constructs related to interpersonal problems that follow the loss of a parent during adolescence. Although social inhibition was not one of those constructs, the research confirms the presence of several characteristics of social inhibition, such as avoidance of and discomfort in relationships. For example, bereaved young adults avoided intimacy and intimate relationships (Hepworth et al., 1984; Meshot \& Leitner, 
1993; Maranzano, 2004), experienced less comfort in close relationships (Kippley, 1998), and scored higher on the Social Introversion scale of the MMPI-168 (Dietrich, 1984). Some young adults avoided intimate relationships because they feared the loss of their partners (Silverman, 1987). Not only is such avoidance consistent with social inhibition, but the nature of the avoidance is congruent with the findings of Fleming and Adolph (1986) who observed that the self concept of parentally bereaved adolescents often includes the belief that if they get close to another, that person will die. Moreover, compared to non-bereaved young adults, those who had experienced parental loss had a stronger desire to be included by their peers despite an opposing tendency to avoid relationships (Meshot \& Leitner, 1993). This suggests that even though avoidance is preferred, bereaved young adults still long to have their communion and agency needs satisfied, which is consistent with contemporary interpersonal theory. Thus, the various studies reviewed support the conclusion that the loss of a parent in adolescence leads to interpersonal disruptions.

However, the inferences drawn must be applied with caution given the methodological shortcomings of the studies. First, the instruments used in some of the studies are either unclear (Jacobson \& Ryder, 1969), lack appropriate psychometric properties (Hepworth et al., 1984), or have questionable construct validity (Kippley, 1998). Second, the sampling procedures used in some studies limit the robustness of the findings. For example, the authors of some studies mixed those who had lost a parent in adolescence with others who had lost a parent during childhood (Jacobson \& Ryder, 1969; Kippley, 1998). In other studies it is not clear when the parent died (Hepworth, et al., 1984; Silverman, 1987). Furthermore, some samples were restricted to bereaved females (Silverman, 1987), while in others only the loss of a father was considered (Kippley, 1998). Moreover, three studies (Hepworth et al., 1984; Kippley, 1998; 
Maranzano, 2004) had a mixed sample drawn from college student and community populations. Finally, aside from the study by Meshot and Leitner (1993), the differences in interpersonal problems between males and females remain unclear.

Most of the above studies also overlooked important developmental factors, such as the tasks of adolescence, cognitive changes, and identity development. Disruption of these necessary developmental tasks would likely lead to later interpersonal problems (Havighurst, 1950). The psychological theory used to explain the inclusion of specific constructs was often vague. Only Meshot and Leitner (1993) and Maranzano (2004) included theory to justify the rationale of their studies. The remaining authors pointed to loss-specific factors such as unresolved grief persisting into young adulthood as the cause for the interpersonal problems. Such rationale seems reasonable, but it is narrowly focused and inconsistent with the rationale proposed here.

\section{Loneliness and Parental Loss in Adolescence}

Like social inhibition, research on loneliness among young adults who lost a parent in adolescence is minimal. Murphy (1986) conducted the only study assessing loneliness among the population in question. Murphy explored whether self-esteem, mourning behavior, age at death, or sex of the deceased parent could predict loneliness. The researcher speculated that loneliness among parentally bereaved young adults existed because they had not participated in grief work during the loss. As such, the Revised UCLA Loneliness Scale, Coopersmith SelfEsteem Inventory, and the Mourning Behavior Checklist were administered to a sample of 184 young adults who lost parents to death between the ages of 3 and 16 . While most of the sample included those who lost parents in adolescence, approximately $27 \%$ experienced parental loss as a child. Preliminary analysis revealed that only age at time of death was a significant predictor 
of loneliness. However, self-esteem was also predictor after age and sex were held constant. Additionally, mourning behavior emerged as a predictor when age, sex, and self-esteem were held constant. These results suggest that older adolescents, those with lower levels of selfesteem, and those with few mourning behaviors are more likely to experience loneliness in young adulthood.

Despite these unique insights between loneliness and loss, Murphy's (1986) study is limited by methodological issues. First, parental loss at ages 3 to 16 were included in this study. Given the wide age range of the sample at the time of loss, the results might not be directly applicable to adolescents when $27 \%$ of the sample experienced parental loss before the age of 10 . Moreover, the source of the sample in the author's study is not mentioned. It remains unknown whether the young adults were from a community or college student population. Finally, consistent with the present study, loneliness was considered as an outcome variable by Murphy. However, Murphy's rationale for including loneliness is considerably different than in the present study. While the present study leans on developmental reasons for why loneliness would arise among young adults who lost a parent in adolescence, Murphy's argument is rooted in lossspecific factors.

\section{Rationale for Current Study}

Social inhibition among young adults who have lost parents during adolescence has never been assessed. Furthermore, social inhibition has not been assessed in conjunction with loneliness. Given the importance of interpersonal relationships on mental health (e.g., Horowitz et al., 1983; Kleiner \& Marshall, 1987) and the associations of interpersonal problems with negative outcomes (e.g., Hartman et al., 2010; Kleiner \& Marshall, 1987; Ogrodniczuk et al., 2009), it is important that social inhibition be explored in conjunction with loneliness, as they are 
likely maladaptive outcomes of losing a parent in adolescence. Understanding how parentally bereaved young adults differ from their non-bereaved peers would help clinicians identify adolescents who are at risk for becoming socially inhibited or lonely. This may be particularly important for those who attend college, as loneliness and isolation have been implicated as negatively influencing retention rates (Kitzrow, 2003).

Identification of at-risk parentally bereaved adolescents would be helpful for several other reasons. First, the bereavement occurs during a 'critical period' of interpersonal development (Blos, 1967; Havighurst, 1972). Adolescence is a time to explore and experiment with interpersonal patterns of behavior. Thus, therapeutic interventions might be more efficacious at this time rather than later because rigid interpersonal behaviors have yet to be established. Second, not only is adolescence an optimal time to intervene, but it is also an urgent time because the bereaved individuals have majority of their lives ahead of them. Given the negative effects of maladaptive interpersonal problems identified in the literature (Hartman et al., 2010; Kleiner \& Marshall, 1987; Ogrodniczuk et al., 2009), knowing that losing a parent in adolescence is associated with future interpersonal deficits could lead to the development of interventions designed to help prevent these negative effects.

\section{Research Questions and Hypotheses}

Given the unexplored relationships among social inhibition and loneliness, and the shortcomings of the studies reviewed above, this project aims to answer the following four research questions: (a) are there differences in social inhibition between bereaved and nonbereaved young adults? (b) are there gender differences in social inhibition among bereaved young adults? (c) are there differences in loneliness between bereaved and non-bereaved young adults? and (d) are there gender differences in loneliness among bereaved young adults? 
Based on these research questions, four directional hypotheses are proposed: (a) bereaved young adults will have higher levels of social inhibition than non-bereaved young adults, (b) bereaved females will have lower levels of social inhibition than bereaved males, (c) bereaved young adults will report higher levels of loneliness than non-bereaved emerging adults, and (d) bereaved females will report lower levels of loneliness than bereaved males. 


\section{Chapter 3}

\section{Participants}

In this study I explored the relationship between social inhibition, loneliness, bereavement status, and gender among college students ages 18 to 30 . This age group was selected because it represents young adulthood and the period of the lifespan when interpersonal relationships are expected to be the foundation of one's identity (Erikson, 1959/1980; 1968). To be included in this study, participants had to meet certain criteria. For the bereaved sample, the participants were limited to young adults between the ages of 18 and 30 who had lost a parent in adolescence; defined as between the ages of 10 and 18. The participants did not include those who lost a parent in childhood (prior to age 10) or young adulthood (after age 18). Additionally, the loss of the parent had to be due to death rather than other types of parental loss, such as divorce, estrangement, or abandonment. Moreover, the loss had to occur at least six months prior to participation to avoid confounding the data with acute grief reactions (Prigerson, Vanderwerker, \& Maciejewski, 2008). There were no exclusions regarding the nature of death as it may be unexpected (e.g., accident) or expected (e.g., illness). For the non-bereaved sample, the participants were young adults between the ages of 18 and 30 who have never lost a parent to death.

The participants in this study included 13 male and 43 female students $(n=56)$ from West Virginia and Montana State Universities: $n=20$ and 36, respectively. The average age was $22(S D=2.67$, range: $18-30$ years). Most participants were White (89\%), followed by Asian American (5\%). More than half had a high school degree (71\%), whereas others had completed an undergraduate degree $(21 \%)$ and a graduate degree $(7 \%)$. 
About $25 \%$ of the students had a parent die in adolescence ( $n=14 ; 7$ men, 7 women). The largest proportion of this group lost their parent when they were 16 years old (35\%) due to unexpected reasons (64\%). All of the bereaved students' parents died at least one year prior to completing the survey and the most frequently reported time since the loss was 4 years (29\%). Most bereaved students lost their father (64\%). Forty-three percent of these students had not experienced any other significant bereavements, while $36 \%$ had experienced one other loss. For complete demographic and frequency statistics, please consult Tables 1 and 2.

The response rate to the questionnaire was 79\%. Questionnaires from 17 participants were not included in the data set because they were partially completed and four were omitted because the responding students did not meet the inclusion criteria. Given the attained sample size and targeted effect size of .30, the post-hoc power estimate for the study was .99 and the standard alpha error rate was maintained at $\alpha=.05$, as calculated by $\mathrm{G}^{*}$ Power (Faul, Erdfelder, Lang, \& Buchner, 2007).

\section{Materials}

An online questionnaire was used to measure the constructs under investigation. The questionnaire consisted of a cover letter, a demographics page, and the instruments used to measure social inhibition and loneliness. The final section of the questionnaire contained a counseling service referral list. The presentation order of the instruments assessing loneliness and social inhibition was randomized to control for presentation effects.

Cover letter. The first page included a cover letter that described the purpose of the study, assurance of confidentiality, and the contact information of the investigators. See Appendices A and B for the cover letters for each university. 
Table 1

Descriptive Statistics for the Total Sample $(N=56)$

Frequencies

School

West Virginia University 20

Montana State University 36

Current Age

18

19

4

20

8

21

12

22

6

23

10

24

4

25

3

26

4

27 to 30

2

3

Race/Ethnicity

African American 1

White $\quad 50$

Asian American 3

Bi-racial/Other $\quad 2$

Education

High School 40

Undergraduate $\quad 12$

Graduate 4

Group Membership ${ }^{1}$

Bereaved Males $\quad 7$

Bereaved

Females

Non-Bereaved Males $\quad 6$

Non-Bereaved Females $\quad 36$

Note. ${ }^{1}$ Includes gender and bereavement status of the participants. 
Table 2

Descriptive Statistics for Loss-Specific Variables Among the Bereaved Sample $(n=14)$

Frequencies

Age of Participant When Bereaved (years)

10

11

12

14

16

17
3

1

1

1

5

3

Time Since Loss (years)

2

3

4

5

6

7

10

11

13 to 18

1

1

4

1

1

2

1

1

2
Gender of Parent

Male

9

Female

5

Type of Death

Expected

5

Unexpected

9

Other Bereavements

0

1

2

3

$4+$
6

5

1

1

1 
Demographic and loss characteristics. Several items assessed the participants' demographic and parental loss characteristics. The demographic information captured was enrolled university, age, gender, race/ethnicity, and highest level of education received. Additionally, participants were asked to indicate their bereavement status, their age at time of loss (if applicable), and the time since the loss (if applicable) to assist in determining whether they met the inclusion criteria and appropriate group membership. Furthermore, the gender of deceased parent, cause of parent's death, and number of prior bereavements was assessed because these factors often lead to poor bereavement outcomes (Stroebe, Folkman, Hansson, \& Schut, 2006; Stroebe \& Schut, 2001; Worden, 2009). In sum, all of these demographic and loss characteristics appear in the descriptive statistics section of the results. Only bereavement status and gender of the participants were included in the main data analysis.

Social inhibition. Social inhibition was measured using the eight-item Socially Inhibited scale of the Inventory of Interpersonal Problems-64 (IIP-64; Horowitz et al., 2003). The IIP-64 is an empirically and theoretically derived instrument originally used with college students (Horowitz, 1979), and later with psychiatric clients (Horowitz et al., 1988), to identify the types of interpersonal problems clients bring into psychotherapy (Horowitz, 1979; Horowitz et al., 1988). Since then, the instrument has been further refined and validated for use with college students (Alden et al., 1990) and other populations. All items on the IIP-64 begin with the statements, "It is hard for me to..." or "The following are things that you do too much." Sample items from the eight-item Socially Inhibited scale include, "I am too afraid of other people," "IIt is hard for me to...] Open up and tell my feelings to another person," and "I feel embarrassed in front of other people too much.” Respondents answer on a 5-point Likert-type scale, from 0 (not at all) to 4 (extremely). 
The IIP-64 and its component scales have demonstrated adequate reliability estimates. According to Horowitz et al., (2003), internal reliability coefficients using Cronbach's Alpha (Cronbach, 1951) for all scales range from $\alpha=.76$ (Domineering/Controlling and Intrusive/Needy scales) to $\alpha=.88$ (Nonassertive scale) based on the standardization sample. The Socially Inhibited scale had a reliability coefficient of $\alpha=.85$ among the standardization sample. Test-retest calculations from a subsample of 60 participants (median retest duration was 7 days) revealed correlations ranging from $r=.58$ to $r=.84$. The Socially Inhibited scale was the upper bound of these test-retest estimates with $r=.84$.

Validity of the IIP-64 and its component scales has been demonstrated (Horowitz et al., 2003). The authors established convergent validity by correlating the IIP-64 standard scores with the Beck Depression Inventory and the Beck Anxiety Inventory, such that the IIP-64 scales shared between $10 \%$ and $23 \%$ of the variance with both measures. Convergent validity was also demonstrated by correlating the standard scores of the instrument's eight scales with those from symptoms checklists, such as the Brief Symptom Inventory and the Symptoms Checklist-90-R. Each scale of the IIP-64 was correlated with these measures, and the Socially Inhibited scale had respective correlations of $r=.71$ and $r=.25$. Furthermore, convergent validity was demonstrated by correlating the responses of the IIP-64 with those obtained on self-reports of general functioning. For example, the Relation to Self/Others $(r=.62)$ and Psychosis $(r=.65)$ subscales of the Behavior and Symptom Identification Scale (BASIS-32) were correlated with the IIP-64 Total Score. The Socially Inhibited scale had the largest correlations with these scales from the BASIS-32 ( $r=.56$ and $r=.61)$. The authors also assessed the relation of the IIP-64's responses to those on the Social Adjustment Scale-Self Report (SAS-SR). Correlations ranged from $r=.16$ to $r=.49$. The Socially Inhibited $(r=.49)$ and Nonassertive $(r=.44)$ scales of the 
IIP-64 correlated highest with the Social and Leisure subscale of the SAS-SR.

Factorial validity and structure of the IIP was originally established by Horowitz (1979), and has been revised several times since then (Alden et al., 1990; Horowitz, 1979; Horowitz et al., 1988). Most recently, Horowitz et al. (2003) found that the factor structure consisted of eight scales located in a two dimensional space in the interpersonal circumplex. The dimensions were termed dominance and affiliation, and the subscales were named: Domineering/Controlling (Scale 1); Vindictive/Self-Centered (Scale 2); Cold/Distant (Scale 3); Socially Inhibited (Scale 4); Nonassertive (Scale 5); Overly Accommodating (Scale 6); Self-Sacrificing (Scale 7); and Intrusive/Needy (Scale 8).

Loneliness. The UCLA Loneliness Scale (Version 3; Russell, 1996) was used to determine participants' current level of loneliness. The UCLA Loneliness Scale (Version 3) consists of 20 items with 11 negatively worded items (i.e., lonely) and 9 positively worded ones (i.e., non-lonely). Sample items include, "How often do you feel alone?" and "How often do you feel there are people you can talk to?" Participants answer on a 4-point Likert-type scale, from 1 (never) to 4 (always).

The psychometric properties of the UCLA Loneliness Scale (Version 3) are well established. According to the author's most recent publication detailing the psychometric properties (Russell, 1996), responses on the UCLA Loneliness Scale (Version 3) have yielded internal consistency values using Cronbach's Alpha ranging from $\alpha=.89$ to .94 across a variety of samples, such as teachers, the elderly, nurses, and college students. Most recent test-retest reliability estimates were $r=.73$ over a one-year period for an elderly sample. Russell (1996) noted that this test-retest coefficient is comparable to those obtained for earlier versions of the scale. 
Validity estimates for the UCLA Loneliness Scale (Version 3) were indentified by correlating the responses from the instrument with those on measures obtained in an earlier study of college students (Russell, 1996). For example, convergent validity was established between the responses on the UCLA Loneliness Scale (Version 3) and those on the NYU Loneliness Scale $(r=.65)$ and the Differential Loneliness Scale $(r=.72)$. Moreover, responses on the UCLA Loneliness Scale (Version 3) were inversely related to responses on the subscales of the Social Support Questionnaire ( $r=-.48$ and $r=-.56$ ); thus providing evidence for discriminant validity of the instrument's responses. Convergent validity was further determined by finding significant correlations between the responses on the UCLA Loneliness Scale (Version 3) and those on neuroticism and introversion-extraversion subscales of the Eysenck Personality Inventory ( $r=.49$ and $r=-.40$, respectively). Furthermore, significant correlations were found between the UCLA Loneliness Scale (Version 3) and measures of depression $(r=.52)$ and selfesteem $(r=.60)$. Given that these correlations were lower than those of the correlated loneliness measures noted above, Russell (1996) suggested that it provides further support for discriminant validity of the UCLA Loneliness Scale (Version 3). Finally, confirmatory factor analysis was used to determine the factor structure of the instrument. Based on that analysis, a single bipolar loneliness factor with two correlated method factors that reflect the positive and negative wording of the items was found to offer the best fit to the data (Russell, 1996), providing evidence for a meaningful factor structure.

Counseling service referral list. The final section of the questionnaire consisted of a list of mental health providers in each university's community (see Appendices C \& D).

\section{Procedure}

Approval to collect data was obtained from the Institutional Review Board (IRB) at West 
Virginia University (WVU) in February of 2013. Montana State University (MSU) accepted WVU as the IRB of record that same month. Data collection commenced on February 15, 2013 and ended May 19, 2013.

Participants were recruited through a variety of methods used in past research in this area (Kippley, 1998; Maranzano, 2004). Flyers advertising the study were posted at each campus's student union building and counseling center. Additionally, 4x6 index cards were placed on the coffee tables in the waiting room of each university's counseling center. A $3 \times 5$ index card was also placed on a bulletin board in the student union building at MSU. Furthermore, the study was advertised in each university's student newspaper (WVU's Daily Athenaeum and MSU's The Exponent) on two separate occasions and also posted on the local editions of Craigslist.com. All flyers and ads contained the same information and were approved by the WVU IRB prior to posting.

The flyers and ads directed the students to complete an online survey hosted by Qualtrics.com. The first 20 bereaved and first 20 non-bereaved students were offered a monetary incentive in the form of $\$ 5$ each for their participation. A total of 36 payments were made; 20 to non-bereaved students and 16 to bereaved students. The author of this study funded these incentives.

\section{Research Design and Statistical Analysis}

Design. This study utilized a quantitative descriptive design. This design is appropriate when researchers aim to describe the characteristics of a particular phenomenon that has been relatively unexplored (Heppner, Wampold, \& Kivlighan, 2008). The data that is derived from such a design can often be the foundation of future experimental intervention studies, which is a goal of this study. Thus, to describe the differences in social inhibition and loneliness among 
bereaved and non-bereaved young adults, an online survey was utilized to measure and capture responses to these variables. Although experimental manipulations were not applied, this design will be high on external validity (i.e., be able to generalize to other adolescents who have lost a parent in adolescence) and low on internal validity (i.e., unable to make claims about causal inference).

Threats to external and internal validity. As with any research, certain limitations and threats to the external and internal validity must to be considered when interpreting the results of the data analysis. Factors such as sample size, relationship between the constructs under investigation, and loss-related constructs not assessed in the study all pose threats to the rigor and generalizability of this study. These and other limitations pertinent to this study will be discussed in Chapter 5.

Statistical analyses. Due to the nature of the research questions and multitude of outcome variables, a multivariate analysis of variance (MANOVA) was used to analyze the differences in loneliness and social inhibition among young adults. A MANOVA is appropriate when there are several dependent variables and one or more independent variables (Weinfurt, 1995). Thus, this statistical procedure clarified whether significant differences exist in social inhibition and loneliness (dependent variables) among bereaved and non-bereaved young adults and the gender of participants (independent variables). The results of this analysis can be found in Chapter 4.

Power analyses. Requisite sample sizes were determined using $\mathrm{G}^{*}$ Power 3.1 for Mac OSX (Faul et al., 2007). Based on preliminary a priori power analysis for a MANOVA: Global Effects, the total sample size required for a medium effect size of $d=.30$ (Cohen, 1988) and a power of .80 (Cohen, 1992) is approximately 28 individuals (14 bereaved and 14 non-bereaved; 
7 per group $)^{6}$. Such an effect size suggests there would be a moderate level of difference between the groups on measures of social inhibition and loneliness. Since there are no prior studies examining these variables in conjunction with the death of a parent in adolescence, empirically established effect size aims are not available. With a larger sample size, a small effect is likely, but probably not clinically useful. With a smaller sample size, it will be more difficult to find an effect. Thus, a medium effect size of $d=.30$ seems appropriate for this explorative study as it would be the smallest effect size that would be clinically meaningful.

A range of methodological compensations was considered if the targeted sample size was not attained. One such compensation included a compromised power analysis (Faul et al., 2007). However, such analysis proved unnecessary given the sample size was adequate for the proposed analysis.

\footnotetext{
${ }^{6}$ Sample size is based on 4 groups ( 2 bereavement status groups; 2 gender of participant groups) and two response variables (social inhibition and loneliness). Alpha level and power inputs were uncompromised and set at their conventional levels of .05 and .80 , respectively.
} 


\section{Chapter 4}

\section{Main Analysis}

Due to the nature of the research questions and multitude of outcome variables, a oneway multivariate analysis of variance (MANOVA) was used to analyze the differences in loneliness and social inhibition among young adults (Weinfurt, 1995). Means and standard deviations for each group can be found in Table 3 .

The MANOVA revealed no significant main effects, Wilks' $\lambda=.90, F(6,102)=.91, p<$ $.491, \eta^{2}=.05$. While the assumption of homogeneity was met, Box's $M=9.99, F(9,2578.53)=$ $.96, p<.470$, hypotheses one through four were not confirmed. There does not seem to be any significant differences in loneliness and social inhibition between bereaved and non-bereaved young adults. In addition, there do not appear to be gender differences in loneliness and social inhibition among bereaved young adults either.

\section{Additional Analyses}

Cone and Foster (2006) recommend conducting additional and unanticipated analyses when there is a lack of significant findings in a research study. The following sections include a one-way multivariate analysis of covariance (MANCOVA), bivariate correlations between the demographics and dependent variables, a second MANOVA with the stage of adolescence at time of loss serving as the grouping variable, and a discriminant analysis on the dependent variables.

MANCOVA. A MANCOVA was conducted to control for extraneous loss-related variables that may affect the results. Thus, gender of the deceased parent, type of death, number of prior bereavements, and time since the loss were assessed as covariates. These variables are potentially important because they have often been associated with and predictive of poor 
Table 3

Mean Loneliness and Social Inhibition Scores for Each Group

$M \quad S D \quad N$

Loneliness

Bereaved Males

Bereaved Females

Non-Bereaved Males

Non-Bereaved Females
47.29

41.43

54.83

47.61

22.14

18.71

26.50

20.89
14.35

5.83

13.36

12.23

6.52

5.50

9.69

7.26
Non-Bereaved Males

Non-Bereaved Females

Note. Higher means indicate greater feelings of loneliness and social inhibition. 
bereavement outcomes among a variety of populations (Stroebe et al., 2006; Stroebe \& Schut, 2001; Worden, 2009). Thus, they could influence the results on the loneliness and social inhibition measures among the bereaved sample.

The MANCOVA revealed no significant main effects, Wilks' $\lambda=.85, F(2,7)=.64, p<$ $.557, \eta^{2}=.15$. Assumption of homogeneity was met, Box's $M=5.87, F(3,25920)=1.60, p<$ .186. Thus, gender of deceased parent, type of death, number of prior bereavements, and time since the loss do not appear to affect loneliness and social inhibition scores among the bereaved sample.

Bivariate correlations. I also explored the bivariate correlations between the dependent and the demographic variables (see Table 4). As one can see, there were two significant correlations, but neither consisted of a demographic variable being associated with loneliness or social inhibition. However, the dependent variables were significantly correlated, $r=.80, p<$ .01 (see discriminant analysis below)

MANOVA \#2 and the stage of adolescence. I also explored whether the stage of adolescence that the bereaved students lost their parent had any relationship to reported levels of loneliness and social inhibition. Bereaved students' responses were grouped according to whether they lost their parent in early, middle, or late adolescence (Balk \& Corr, 2001). A second one-way MANOVA was conducted that revealed a significant effect for the stage of adolescence, Wilks' $\lambda=.58, F(2,11)=3.99, p<.050, \eta^{2}=.42$ (see Table 5 for means and standard deviations). The assumption of homogeneity was met, Box's $M=1.41, F(3,9784.23)$ $=.38, p<.766$.

To explore differences between the stages of adolescence, two one-way analyses of variance (ANOVAs) were carried out for each dependent variable. The ANOVA for loneliness 
Table 4

Bivariate Correlations for Demographic and Dependent Variables

\begin{tabular}{|c|c|c|c|c|c|c|c|}
\hline & School & Age & Gender & Ethnicity & Education & Loneliness & Social Inhibition \\
\hline School & -- & & & & & & \\
\hline Age & -0.05 & -- & & & & & \\
\hline Gender & 0.03 & 0.02 & -- & & & & \\
\hline Ethnicity & 0.01 & -0.09 & 0.15 & -- & & & \\
\hline Education & -0.17 & $0.45^{* *}$ & 0.11 & 0.06 & -- & & \\
\hline Loneliness & -0.06 & 0.11 & -0.15 & 0.00 & 0.12 & -- & \\
\hline Social Inhibition & 0.16 & 0.07 & -0.21 & -0.03 & 0.06 & $0.80 * *$ & -- \\
\hline
\end{tabular}

Note. **Correlation is significant at the .01 level. 
Table 5

Mean Loneliness and Social Inhibition Scores for the Bereaved Sample by Stage of Adolescence

$M \quad S D \quad N$

Loneliness

$\begin{array}{lccc}\text { Early }(10 \text { to } 14 \text { years }) & 42.83 & 10.09 & 6 \\ \text { Middle }(15 \text { to } 17 \text { years }) & 45.50 & 12.11 & 8 \\ \text { Late }(18 \text { to } 22) & - & - & 0\end{array}$

Social Inhibition

Early (10 to 14 years

17.00

4.86

6

Middle (15 to 17 years)

23.00

5.81

8

Late (18 to 22 )

- $\quad-\quad 0$

Note. Higher means indicate greater feelings of loneliness and social inhibition. 
was non-significant, $M S=24.38, F(1,12)=.19, p<.670, \eta^{2}=.02$, while the ANOVA for social inhibition was also non-significant, $M S=123.43, F(1,12)=4.18, p<.063, \eta^{2}=.26$. These non-significant ANOVAs suggest that the significant differences revealed by the MANOVA are due to the correlation between loneliness and social inhibition. ANOVAs do not take into account this relationship; thus a discriminant analysis must be performed to further clarify the group differences (Field, 2005).

Discriminant analysis. A discriminant analysis was performed that considered the stages of adolescence as the grouping variables and the total loneliness and social inhibition scores as the independent variables. Based on this analysis, one significant variate emerged that accounted for $100 \%$ of the variance (eigenvalue $=.73$, Wilks' $\lambda=.58, p<.050$ ). That variate had discriminant function coefficients of -1.25 for loneliness and 1.71 for social inhibition. Based on these numbers, social inhibition appears to have a greater contribution to the variate than loneliness. Also, the divergent polarities $(+,-)$ indicate that these dependent variables are contributing to the variate in qualitatively different ways. Finally, based on the functions at group centroids (early adolescence $=-.91$; middle adolescence $=.68$ ), it appears that those who lost their parent in middle adolescence are most affected by this variate. With that said, the group differences identified in the second MANOVA seem to be explained by a single underlying dimension (i.e., variate) not directly assessed in this study. That dimension seems to cause some form of interpersonal disruption in middle adolescence that both the loneliness and social inhibition measures partially captured. 


\section{Chapter 5}

The four proposed hypotheses were not supported by the data in this study. The predicted differences in loneliness and social inhibition between bereaved versus non-bereaved young adults who attend college were not found. Furthermore the hypothesized gender differences in loneliness and social inhibition were not evident in the bereaved sample. Additional analyses were conducted to explore the impact of loss-related variables, but those analyses proved mostly unfruitful. However, the stage of adolescence in which bereaved young adults lost their parents seems to be associated with various degrees of interpersonal disruption, particularly in middle adolescence. The implications of this finding will be discussed more fully below.

\section{Integration of Findings with Past Literature}

Overall the literature exploring the developmental and psychological implications of bereavement and loss among adolescents and college-age young adults is relatively sparse. However, the research reviewed for this study did point to the existence of interpersonal problems among young adults who lost their parents in adolescence, such as problems with intimacy and general interpersonal functioning (Maranzano, 2004; Meshot \& Leitner, 1993).

The present study was designed to improve upon the methodological shortcomings of these past research efforts (e.g., instrumentation, precise age range of adolescence, theory, etc.) hoping to determine how bereaved and non-bereaved college students differ on measures of social inhibition and loneliness. Unexpectedly the data collected for this study did not replicate the findings of prior researchers who surveyed interpersonal problems among parentally bereaved young adults. Thus it is puzzling that the hypothesized differences between the groups did not emerge. However, several potential sources of these discrepant findings emerge when 
one considers the sampling, statistical and instrumental, and conceptual limitations of the current study.

\section{Sampling Issues}

The number of participants comprising the bereaved sample was relatively low in this study. Researchers in this area typically were able to enroll 18 to 57 bereaved young adults attending college (Hepworth et al., 1984; Silverman, 1987), but this study enrolled only 14 bereaved individuals. While the minimum sample size required to achieve adequate statistical power was met, the small sample size could have obscured the differences between groups as evident by the low effect sizes and power estimates attained in the MANOVA. Limited sampling procedures and scope of the participant pool (i.e., only college students sampled from two campuses) likely contributed to the small sample size of the bereaved group.

The origin of the sample itself could have impacted the results. Samples captured in past research originated from urban campuses (Maranzano, 2004). However, a majority of the current sample came from Montana State University (MSU), which is set in a rural community in the northwestern region of the United States. While students at MSU likely have similar collegiate experiences as those attending other universities (e.g., academic, relational, and developmental stressors), many of them were raised on rural ranches and may have been geographically isolated from other people for much of their lives. This could have an effect on how these students responded to some of the survey items. For example, consider the items from the UCLA Loneliness Scale (Version 3), "how often do you feel isolated from others," and "how often do you feel there are people you can turn to?" These items seem to suggest that being isolated is non-normative and there should be people to 'turn to'-two concepts that may be not be entirely applicable for those who were raised in these rural settings. 
The backgrounds of MSU students may have had other effects. Student who grew up on ranches and farms may have been more exposed to injury and death (e.g., machinery accidents, farm animals, etc.) such that loss may be a normative experience for them, more or less, than those who grow up in suburban regions of the United States. However, in contrast to those who grew up geographically isolated, other students from MSU were raised in small communities with large close-knit extended families. While these students' communities may have been isolated, they may have not felt as isolated as those who grew up on a ranch. All of these background factors of MSU students may have buffered and obscured the effects of loss or feelings of social inhibition and loneliness.

Lack of random sampling likely reduced the external validity of the results. A convenience sample was used in this study given the exploratory nature of the research questions. That sample is comprised of young adults who attend college, congregate in university areas where many of the advertisements were placed (e.g., union building, counseling centers), and were willing and motivated to complete a survey. Without random sampling from the population of interest, the responses to the measures may have been biased; the participants may have been more or less isolated and socially inhibited than those in the general population. Thus, the results may not generalize to other bereaved young adults who attend college as well as those in the general population.

Implications and suggestions for sampling issues. As in much research in the social and behavioral sciences, increasing the sample size would greatly increase the likelihood of significant findings. Broadening the participant pool and randomly sampling young adults in the community who don't attend college would also enhance sample size, possibly revealing meaningful differences among the variables of interest. While community samples may differ 
from college student samples in a variety of ways, targeting community samples (in addition to college samples) could help increase sample sizes among the bereaved group. Future researchers could solicit participation at community mental health centers, through public newspapers, and on bereavement web forums or listservs. Also, placing flyers in more locations on campus where college students tend to gather (e.g., residence halls, large study halls, etc.) would likely help maximize sample size in a university or college setting.

\section{Statistical and Instrumentation Issues}

While the dependent measures had strong psychometric properties, they were significantly and strongly intercorrelated. The correlation between loneliness and social inhibition was .80 and the discriminant analysis highlighted the potential nature of this relationship. Therefore, the measures used to assess the constructs under investigation appear to be statistically redundant and lack independence from one another. While this does not have a major impact on reliability or validity, it decreases statistical efficiency as the outcome measures seem to be assessing the same construct twice. Collinearity also seems to increase the statistical 'noise' in a discriminant analysis, thus creating larger error terms (Næs \& Mevik, 2001). However, the results of a discriminant analysis are generally not significantly impacted by these elevations. See Næs and Mevik (2001) for a relevant discussion.

\section{Implications and suggestions for statistical and instrumentation issues. New} instruments and outcome measures could be devised that attend to the underlying dimension or variate not assessed in this study. The dimension identified was a result of the shared variance between loneliness and social inhibition. As noted in Chapter 1, loneliness and social inhibition are both affective states. Loneliness arises from a "relational deficit" (Weiss, 1973, p. 18) whereas social inhibition is characterized by feelings of anxiety while interacting with other 
people (Horowitz et al., 2003). In other words, loneliness is experienced in the absence of others (distance), and the anxiety that accompanies social inhibition is felt while trying to engage and connect with others (closeness). Both affective experiences seem to be the byproduct of not getting one's interpersonal communion needs met. Communion needs are those that make people want to form intimate and selfless relationships with others (Bakan, 1966; Horowitz, 2004). Based on the discriminant analysis, parentally bereaved adolescents seem to have difficulty connecting with others. Thus, a new outcome measure might be constructed to tap into the communal experience of parentally bereaved young adults in ways the UCLA Loneliness and Socially Inhibited scales could not.

\section{Conceptual and Theoretical Issues}

Other issues derive from the theoretical underpinnings of this study. Past researchers in this area have omitted theoretical and developmental factors when developing their research questions. However, in this study I based my hypotheses on the theories originally proposed by Havighurst (1950; 1972), Erikson (1959/1980; 1968), and Elkind (1967; 1981). The developmentally oriented propositions made by these authors lead one to conclude that loneliness and social inhibition would emerge as likely interpersonal problems for bereaved young adults. While these theories are empirically and clinically useful to explain the phenomena associated with adolescence, they are perhaps not sufficiently nuanced to allow for specific predictions about the types of interpersonal problems that would emerge in young adulthood for the population under study.

In addition, the theories used in this study may have aged a bit. For example, around the time of Erikson's (1959/1980) original works, most late adolescents and early young adults were settling into long term careers, getting married, and having children. Contemporary 
developmental authors such as Arnett $(2000,2004,2007)$ make the case that this traditional way of exiting adolescence no longer captures the experience of this age group. Instead of one's identity being resolved by the end of adolescence (Erikson, 1959/1980), Arnett proposes that identity formation persists into the mid to late twenties. If this is the case, the developmental tasks that were hypothesized to be disrupted by the death of a parent in adolescence may not have been affected at all, as the results of this study seem to indicate.

There were also a multitude of loss-related variables not assessed in this study. While several loss-related variables were controlled for in the MANCOVA, they did not significantly impact the group differences. Other variables such as the participants' attachment styles, degrees of attachment with bereaved parent, current grief symptoms, social support, and the relationships with their surviving parental figures might have affected between-group differences in loneliness and social inhibition.

\section{Implications and suggestions for conceptual and theoretical issues. Researchers}

could base future studies on theoretical models that predict specific developmental tasks during the various stages of adolescence. For example, Fleming and Adolph (1986) note that specific developmental conflicts arise at different stages of adolescence that are accompanied by various cognitive, behavioral, and affective responses. These conflicts are said to be disrupted when an adolescent experiences bereavement during this time of the lifespan. Thus, developing hypotheses from such a model could provide more conceptual specificity and subtlety concerning the types of interpersonal problems one may expect to find among young adults who lost parents in adolescence. The results of the discriminant analysis suggest that middle adolescence could be an important starting point for exploration within this theoretical framework. 
In addition, it may be helpful to base future studies in this area on contemporary models of development, such as those proposed by Arnett $(2000,2004,2007)$. While Arnett does not hypothesize about the tasks of adolescence, his contributions to understanding the challenges of young adulthood are illuminating. Researchers who wish to explore how young adults are affected by the death of a parent in adolescence may lean on Arnett's findings to enhance the precision of their hypotheses.

Finally, the results do not rule out loneliness and social inhibition as significant and meaningful issues among parentally bereaved young adults. Based on the theories discussed in this paper, the loss of a parent appears to negatively impact the self-concept of these individuals in ways that limits important developmental experiences with peers. The thwarting of these experiences seems to frustrate their communion and control needs; leaving them lonely, socially inhibited, and lacking "interpersonal competence" (Horowitz et al., 1982, p. 185). Therefore, these problems may exist for this population, but it is difficult to determine how these experiences are being processed and understood in a more general way among young adults, given the small sample size of the current study.

Although the empirical grounding of these constructs was not evident in the data collected for this study, it still could be useful for mental health professionals to explore loneliness and social inhibition with parentally bereaved adolescents and young adults. For example, students seek services at college counseling centers for a variety of concerns, such as anxiety, depression, trauma, and loss (National Alliance on Mental Illness, 2013). Regardless of the presenting problem, the underlying issue can be conceptualized as an interpersonal problem (Horney, 1945; Horowitz, 2004; Sullivan, 1953). Thus, mental health professionals who work with parentally bereaved students in these settings may want to probe about the stage of 
adolescence that the loss occurred even if interpersonal problems or grief are not the presenting issues. Such exploration may reveal how they were developmentally and interpersonally impacted by the event, especially if the loss occurred in middle adolescence. Loneliness and social inhibition may emerge after processing the loss. However, other factors not directly assessed in this study could be brought to light as well. Nonetheless, exploring the developmental context for which the loss occurred could inform appropriate course of treatment and specific developmental and interpersonal interventions.

\section{Personal Experience - Revisited}

The results of this research do not directly confirm my experience of losing my own mother when I was an adolescent. After she died, there were times during adolescence and young adulthood when I felt incredibly lonely and anxious when trying to connect with others. However, given the results of the discriminant analysis maybe the loss had a deeper effect on me than just feeling lonely or socially inhibited.

What exactly was experienced on a deeper level is difficult to pinpoint, but it could be significant changes to the self-concept. Perhaps the loss creates a sense of 'badness' or 'unloveableness' - as one gets close to another, that person may die. As noted earlier, parentally bereaved young adults who define themselves with such descriptors are unlikely to engage in healthy relationships with others (Fleming \& Adolph, 1987; Worden, 1996). In the absence of those relationships, the ability to learn adaptive interpersonal behavior, such as how to communicate thoughts and feelings, would certainly be thwarted. However, what might be most affected by the lack of interpersonal engagement are missed opportunities to have those negative self-perceptions disconfirmed by the peer group (Weiss, 1973).

The developmental particulars of middle adolescence deserve attention as well. The 
results of the discriminant analysis suggested that losing a parent during this stage of adolescence causes the most interpersonal disruption. As noted above, this disruption seems to be an affective state centered on not getting one's communal needs met (Bakan, 1966; Horowitz, 2004). While the tension between attaining one's communal and agency needs persists throughout one's life (Kegan, 1982), adolescents at this stage of development are struggling to develop and achieve mastery and control over their lives (Fleming \& Adolph, 1987). When a parent dies during middle adolescence, their sense of mastery and control are shattered; they realize how little control they have over life events and relationships. They may have a variety of emotional responses to this event at this stage, such as fearing one's personal death, feeling rejected and misunderstood by others, or fearing further abandonment, among many others (Fleming \& Adolph, 1987). Thus, it would seem likely that the loss of a parent would threaten these adolescents' global sense of self-efficacy. This may be particularly evident with regard to relationships, where bereaved adolescents may think, "What is the point of getting close to others?-those people may leave me too."

There is also the issue of the identification. Generally speaking, the identifications children make with their parents through mirroring, idealizing, and twinship experiences are said to be the foundation of their sense of self and esteem (Kohut, 1977; Kohut \& Wolf, 1978). These identifications continue through adolescence until a fully formed identity has been constituted by young adulthood (Erikson, 1959/1980). If a caregiver dies before the adolescent's identity has been completed, that person's sense of self might have not been fully validated or confirmed. In some ways, the adolescent's identity and self would be in developmental moratorium without the appropriate parental object to complete it. To revisit a quote noted earlier, the individual with an incomplete identity "shies away from interpersonal intimacy... and 
comes to retain a deep sense of isolation" (Erikson, 1968, pp. 135-136).

Identity status and formation have been previously studied among parentally bereaved young adults (Maranzano, 2004). In that study, Maranzano found that bereaved young adults had lower identity statuses than their non-bereaved counterparts. However, what was unclear was the qualitative makeup of those identities; the particular pathogenic beliefs about self and whether the self-concept is related to one's identity status. Therefore, mental health professionals and researchers who work with and study this population will hopefully explore the effects of the loss beyond loneliness and social inhibition into the realm of the self-concept and identity.

\section{Conclusions}

Although the predicted differences in loneliness and social inhibition among bereaved versus non-bereaved college students were not found in this sample, it seems unlikely that the impact of parental loss in childhood and adolescence would be insignificant. However the social and psychological processes affected by this loss may be more subtle, complex and interwoven with a variety of developmental tasks that they might not emerge from a relatively brief questionnaire. There may well be more profound effects of parental bereavement on identity formation, the sense of self, and personality integration that future research in this area will reveal. 


\section{References}

Alden, L. E., \& Phillips, N. (1990). An interpersonal analysis of social anxiety and depression. Cognitive Therapy and Research, 14, 499-513.

Alden, L. E., Wiggins, J. S., \& Pincus, A. L. (1990). Construction of circumplex scales for the inventory of interpersonal problems. Journal of Personality Assessment, 55, 521-536.

American Psychiatric Association (2000). Diagnostic and Statistical Manual-IV-TR. (4th ed., Text Revision). Washington, DC: American Psychiatric Association.

American Psychological Association. (2007). APA dictionary of psychology. Washington, DC: American Psychological Association.

Arnett, J. J. (1999). Adolescent storm and stress, reconsidered. American Psychologist, 54, 317-326.

Arnett, J. J. (2000). Emerging adulthood: A theory of development from the late teens through the twenties. American Psychologist, 55, 469-480.

Arnett, J. J. (2004). Emerging adulthood: The winding road from the late teens through the twenties. New York: Oxford University Press.

Arnett, J. J. (2007). Emerging adulthood: What is it, and what is it good for? Child Development Perspectives, 1, 68-73.

Bakan, D. (1966). The duality of human existence: Isolation and communion in Western man. Boston: Beacon Press.

Balk, D. E. \& Corr, C. A. (2001). Bereavement during adolescence: A review of research. In M. S. Stroebe, R. O. Hansson, W. Stroebe \& H. Schut (Eds.), Handbook of bereavement research: Consequences, coping, and care (pp. 199-218). Washington, DC: American Psychological Association. 
Berry, M. (1999). Grief and psychosexual disturbance following the death of a young baby: Some issue for practitioners. Sex and Marital Therapy, 14, 27-42.

Blatt, S. J. (1990). Interpersonal relatedness and self-definition: Two personality configurations and their implications for psychopathology and psychotherapy. In J. L. Singer (Ed.), Repression and dissociation (pp. 299-335). Chicago: University of Chicago Press.

Blos, P. (1967). The second individuation process of adolescence. The Psychoanalytic Study of the Child, 22, 162-186.

Bowlby, J. (1969). Attachment and loss: Vol. 1. Attachment. New York: Basic Books.

Bowlby, J. (1973). Attachment and loss: Vol. 2. Separation: Anxiety and anger. New York: Basic Books.

Bowlby, J. (1980). Attachment and loss: Vol. 3. Loss: Sadness and depression. New York: Basic Books.

Broderick, P. C., \& Blewitt, P. (2010). The life span: Human development for helping professionals (3rd ed.). Upper Saddle River, NJ: Pearson.

Brooks-Gunn, J., Graber, J. A., \& Paikoff, R. L. (1994). Studying links between hormones and negative affect: Models and measures. Journal of Research on Adolescence, 4, 469-486.

Buchanan, C. M., Eccles, J. S., \& Becker, J. B. (1992). Are adolescents the victims of raging hormones: Evidence for activational effects of hormones on moods and behavior in adolescence. Psychological Bulletin, 111, 62-107.

Cohen, J. (1988). Statistical power analysis for the behavioral sciences (2nd ed.). Hillsdale, NJ: Erlbaum.

Cohen, J. (1992). A power primer. Psychological Bulletin, 112, 155-159. 
Cone, J. D., \& Foster, S. L. (2006). Dissertations and theses from start to finish: Psychology and related fields (2nd ed.). Washington, DC: American Psychological Association.

Corr, C. A. (1993). Coping with dying: Lessons that we should and should not learn from the work of Elisabeth Kübler-Ross. Death Studies, 17, 69-83.

Cronbach, L. J. (1951). Coefficient alpha and the internal structure of tests. Psychometrika, 16, 297-334.

Dietrich, D. (1984). Psychological health of young adults who experienced early parent death: MMPI trends. Journal of Clinical Psychology, 40, 901-908.

Doumas, D. M., Blasey, C. M., \& Mitchell, S. (2006). Adult attachment, emotional distress, and interpersonal problems in alcohol and drug dependency treatment. Alcoholism Treatment Quarterly, 24, 41-54.

Elkind, D. (1967). Egocentrism in adolescence. Child Development, 38, 1025-1031.

Elkind, D. (1981). Children and adolescents: Interpretive essays on Jean Piaget (3rd ed.). New York: Oxford University Press.

Erickson, E. H. (1959/1980). Identity and the Life Cycle. New York, NY: W. W. Norton \& Company, Inc. (Original work published 1959).

Erickson, E. H. (1968). Identity, Youth and Crisis. New York, NY: W. W. Norton \& Company, Inc.

Epstein, S. (1973). The self-concept revisited: Or a theory of a theory. American Psychologist, 28, 404-416.

Faul, F., Erdfelder, E., Lang, A.-G., \& Buchner, A. (2007). G*Power 3: A flexible statistical power analysis program for the social, behavioral, and biomedical sciences. Behavior Research Methods, 39, 175-191. 
Field, A. (2005). Discovering statistics using SPSS (2nd ed.). Thousand Oaks, CA: Sage Publications, Ltd.

Fleming, S. J. \& Adolph, R. (1986). Helping bereaved adolescents: Needs and responses. In C. C. Corr \& J. N. McNeil (Eds.), Adolescence and death (pp. 97-118). New York, NY: Springer Publishing Company, Inc.

Garber, B. (1985). Mourning in adolescence: Normal and pathological. Adolescent Psychiatry, 12, 371-387.

Gelso, C. \& Fretz, B. (2001). Counseling psychology (2nd ed.). Belmont, CA: Wadsworth.

Hall, G. S. (1904). Adolescence: Its psychology and its relation to physiology, anthropology, sociology, sex, crime, religion, and education (Vols. I \& II). Englewood Cliffs, NJ: Prentice-Hall.

Hatmann, A., Zeeck, A., \& Barrett, M. S. (2010). Interpersonal problems in eating disorders. International Journal of Eating Disorders, 43, 619-627.

Havighurst, R. J. (1950). Developmental tasks and education. New York: Longmans, Green, and Co.

Havighurst, R. J. (1972). Developmental tasks and education (3rd ed.). New York: David McKay Company, Inc.

Heppner, P. P., Wampold, B. E., \& Kivlighan, D. M. (2008). Research Design in Counseling (3rd ed.). Belmont, CA: Thompson Brooks/Cole.

Hepworth, J., Ryder, R. G., Dreyer, A. S. (1984). The effects of parental loss on the formation of intimate relationships. Journal of Marital and Family Therapy, 10, 73-82.

Horney, K. (1945). Our inner conflicts. New York: W.W. Norton \& Company, Inc. 
Horowitz, L. M. (2004). Interpersonal foundations of psychopathology. Washington, DC: American Psychological Association.

Horowitz, L. M., Alden, L. E., Wiggins, J. S., \& Pincus, A. L. (2003). Inventory of Interpersonal Problems: Manual. Mind Garden, Inc. www.mindgarden.com.

Horowitz, L. M., Dryer, D. C., \& Krasnoperova, E. N. (1997). The circumplex structure of interpersonal problems. In R. Plutchik \& H. R. Conte (Eds.), Circumplex Models of Personality and Emotions (pp. 347-384). Washington, DC: American Psychological Association.

Horowitz, L. M., \& French, R. de S. (1979). Interpersonal problems of people who describe themselves as lonely. Journal of Consulting and Clinical Psychology, 47, 762-764.

Horowitz, L. M., French, R. de S., \& Anderson C. A. (1982). The prototype of a lonely person. In L. A. Peplau \& D. Perlman (Eds.), Loneliness: A sourcebook of current theory, research, and therapy (pp. 183- 205). New York: Wiley.

Horowitz, L. M., Rosenberg, S. E., Baer, B. A., Ureno, G., \& Villasenor, V. S. (1988). Inventory of interpersonal problems: Psychometric properties and clinical applications. Journal of Consulting and Clinical Psychology, 56, 885-892.

Horowitz, L. M., \& Vitkus, J. (1986). The interpersonal basis of psychiatric symptoms. Clinical Psychology Review, 6, 443-469.

Horowitz, L. M., Weckler, D. A., \& Doren, R. (1983). Interpersonal problems and symptoms: A cognitive approach. In P. C. Kendall (Ed.), Advances in cognitive-behavioral research and therapy (Vol. 2, pp. 81-125). New York: Academic Press.

Inhelder, B., \& Piaget, J. (1955/1958). The growth of logical thinking from childhood to adolescence. New York: Guilford Press. 
Jacobson, G., \& Ryder, R. G. (1969). Parental loss and some characteristics of the early marriage relationship. American Journal of Orthopsychiatry, 39, 779-787.

Kegan, R. (1982). The evolving self: Problem and process in human development. Cambridge, MA: Harvard University Press.

Kernhof, K., Kaufhold, J., \& Grabhorn, R. (2008). Object relations and interpersonal problems in sexually abused female patients: An empirical study with the SCORS and the IIP. Journal of Personality Assessment, 90(1), 44-51.

Kiesler, D. S. (1983). The 1982 interpersonal circle: A taxonomy for complementarity in human transactions. Psychological Review, 30, 185-214.

Kipply, T. A. (1998). The long-term impact of parental death of child and adolescent offspring. Unpublished doctoral dissertation, George Mason University, Fairfax, VA.

Kitzrow, M.A. (2003). The mental health needs of today's college students: Challenges and Recommendations. NASPA Journal, 41,165-179.

Klein, M. (1935). A contribution to the psychogenesis of manic-depressive states. In Contributions to psychoanalysis, 1921-1945. New York, McGraw-Hill, 1964.

Kleiner, L., \& Marshall, W. L. (1987). The role of interpersonal problems in the development of agoraphobia with panic attacks. Journal of Anxiety Disorders, 1, 313-323.

Kohut, H. (1977). The restoration of self. New York: International Universities Press.

Kohut, H. \& Wolf, E. (1978). The disorders of the self and their treatment: An outline. International Journal of Psychoanalysis, 59, 413-425.

Kübler-Ross, E. (1969). On death and dying. New York, NY: Scribner. 
Lawson, D. M., \& Brossart, D. F. (2009). Attachment, interpersonal problems, and treatment outcome in group therapy for intimate partner violence. Psychology of Men \& Masculinity, 10, 288-301.

Leary, T. (1957). Interpersonal diagnosis of personality: A functional theory and methodology for personality evaluation. New York: The Ronald Press Company.

Leising, D., Rehbein, D., \& Eckardt, J. (2009). The inventory of interpersonal problems (IIP64) as a screening measure for avoidant personality disorder. European Journal of Psychological Assessment, 25, 16-22.

Lunde, I., \& Ortmann, J. (1990). Prevalence and sequelae of sexual torture. The Lancet, 336, 289-291.

Maranzano, V. (2004). The nature of identity and intimacy in parentally bereaved young adults. Unpublished doctoral dissertation, Columbia University, New York, NY.

Mahler, M. S. (1974). Symbiosis and individuation: The psychological birth of the human infant. Psychoanalytic Study of the Child, 29, 89-106.

McCarthy, G., \& Maughan, B. (2010). Negative childhood experiences and adult love relationships: The role of internal working models of attachment. Attachment and Human Development, 12, 445-461.

Meshot, C. M., \& Leitner, L. M. (1993). Death threat, parental loss, and interpersonal style: A personal construct investigation. Death Studies, 17, 319-332.

Mills, B., \& Turnbull, G. (2004). Broken hearts and mending bodies: the impact of trauma on intimacy. Sexual and Relationship Therapy, 19, 265-289.

Murphy, P. A. (1986). Parental death in childhood and loneliness in young adults. OMEGA, 17, 219-228. 
National Alliance on Mental Illness. (2013). Learn about the issue. Retrieved April 19, 2013, from http://www.nami.org/Content/NavigationMenu/Find_Support/NAMI_on_Campus1/Learn _About_The_Issue/Learn_About_The_Issue.htm

Næs, T., \& Mevik, B-H. (2001). Understanding the collinearity problem in regression and discriminant analysis. Journal of Chemometrics, 15, 413-426.

Ogrodniczuk, J. S., Piper, W E., Joyce, A. S., Steinberg, P. L., \& Duggal, S. (2009). Interpersonal problems associated with narcissism among psychiatric outpatients. Journal of Psychiatric Research, 43, 837-842.

Parkes, C. M. (2001). A historical overview of the scientific study of bereavement. In M. S. Stroebe, R. O. Hansson, W. Stroebe \& H. Schut (Eds.), Handbook of bereavement research: Consequences, coping, and care (pp. 25-45). Washington, DC: American Psychological Association.

Pincus, A. L., \& Wiggins, J. S. (1990). Interpersonal problems and conceptions of personality disorders. Journal of Personality Disorders, 4, 342-352.

Prigerson, H. G., Vanderwerker, L. C., \& Maciejewski, P. K. (2008). A case for inclusion of prolonged grief disorder in the DSM-V. In M. S. Stroebe, R. O. Hansson, W. Stroebe, \& H. Schut (Eds.), Handbook of bereavement research and practice: Advances in theory and intervention (pp. 165-186). Washington, DC: American Psychological Association.

Reiter, E. O., \& Grumbach, M. M. (1982). Neuroendocrine control mechanisms and the onset of puberty. Annual Review of Physiology, 44, 595-613.

Russell, D. W. (1996). ULCA Loneliness Scale (Version 3): Reliability, validity, and factor structure. Journal of Personality Assessment, 66, 20-40. 
Silverman, P. R. (1987). The impact of parental death on college-age women. Psychiatric Clinics of North America, 10, 387-404.

Stepp, S. D., Morse, J. Q., Yaggi, K. E., Reynolds, S. K., Reedm L. I., \& Pilkonis, P. A. (2008). The role of attachment styles in interpersonal problems in suicidal-related behaviors. Suicide and life-threatening behavior, 38, 592-607.

Stroebe, M. (1992). Coping with bereavement: A review of the grief work hypothesis. OMEGA, $26,29-42$.

Stroebe, M. S., Folkman, S., Hansson, R. O., \& Schut, H. (2006). The prediction of bereavement outcome: Development of an integrative risk factor framework. Social Science \& Medicine, 63, 2240-2451.

Stroebe, M., \& Schut, H. (2001). Risk factors in bereavement outcome: A methodological and empirical review. In M. S. Stroebe, R. O. Hansson, W. Stroebe, \& H. Schut (Eds.), Handbook of bereavement research: Consequences, coping, and care (pp. 349-371). Washington, DC: American Psychological Association.

Stroebe, M., \& Schut, H. (2005). To continue or relinquish bonds: A review of consequences for the bereaved. Death Studies, 29, 477-494.

Stroebe, M., Schut, H., \& Abakoumkin (1996). The role of loneliness and social support in adjustment to loss: A test of attachment versus stress theory. Journal of Personality and Social Psychology, 70, 1241-1249.

Sugar, M. (1968). Normal adolescent mourning. American Journal of Psychotherapy, 32, 258269.

Sullivan, H. S. (1953). The interpersonal theory of psychiatry. New York: Norton. 
Vassallo, S., Smart, D., Sanson, A., Harrison, W., Harris, A., Cockfield, S., \& McIntyre, A. (2007). Risky driving among Australian drivers: Trends, precursors and correlates. Accident Analysis and Preventions, 39, 444-458.

Weinberger, M. I., Hofstein, Y., \& Whitbourne, S. K. (2008). Intimacy in young adulthood as a predictor of divorce in midlife. Personal Relationships, 15, 551-557.

Weinfurt, K. W. (1995). Multivariate analysis of variance. In L. Grimm, \& P. R. Yarnold (Eds.), Reading and understanding multivariate statistics (pp. 245-276). Washington, DC: American Psychological Association.

Weiss, R. S. (1973). Loneliness: The experience of emotional and social isolation. Cambridge, MA: The MIT Press.

Wiggins, J. S. (1979). A psychological taxonomy of trait-descriptive terms: The interpersonal domain. Journal of Personality and Social Psychology, 37, 395-412.

Wikipedia. (2012, February 21). Sturm und Drang. Retrieved March 4, 2012, from http://en.wikipedia.org/wiki/Sturm_und_Drang

Worden, J. W. (1996). Children and grief: When a parent dies. New York, NY: Guilford Press.

Worden, J. W. (2009). Grief counseling and grief therapy: A handbook for the mental health professional (4th ed.). New York, NY: Springer Publishing Company, Inc.

Yalom, I. D., \& Leszcz, M. (2005). The theory and practice of group psychotherapy (5th ed.). New York, NY: Basic Books.

Youngren, M. A., \& Lewinsohn, P. M. (1980). The functional relation between depression and problematic interpersonal behavior. Journal of Abnormal Psychology, 89, 333-341.

Zeruch, G., Anat, B-D., Solomon, Z., Heruti, R. (2009). Posttraumatic symptoms, marital 
intimacy, dyadic adjustment, and sexual satisfaction among ex-prisoners of war. International Society for Sexual Medicine, 7, 2739-2749. 
Appendix A

\section{Cover Letter to Serve as a Participant in Research (WVU)}

You are being asked to participate in a research study by Adam Moller, M.S. who is under the supervision of Dr. James Bartee. Adam is a doctoral student and Dr. Bartee is the Training Director in the Department of Counseling, Rehabilitation Counseling, and Counseling Psychology at West Virginia University, Morgantown, WV. Before you agree to participate, please read this form to ensure that you understand the purpose of this project and what your participation will involve.

Purpose of the Research

The purpose of this study is to explore the experiences of young adults have who lost a parent in adolescence.

Time Needed

It will take about 15 to 20 minutes to complete the questionnaire.

Voluntary Participation

Your participation is completely voluntary, and you may withdraw at any time. Although the research will be helped if you answer all of the questions, you can skip any item that you wish not to answer. There will never be any negative consequences for non-participation or non-completion.

Benefits of the Research

There may not be any direct benefits to you from this study. However, your responses will help future young adults who have lost a parent in adolescence.

\section{Compensation for Participation}

As compensation for participating in this study, the first 20 bereaved and first 20 non-bereaved will be awarded $\$ 5$ if you provide your mailing address at the end of the survey.

\section{Procedures and Risks}

If you chose to participate in this study, you will be asked to provide demographic information and complete two questionnaires. Filling out these questionnaires may bring up upsetting thoughts or feelings. If this occurs, you may withdraw from the study at any time. If you feel the need to talk with someone after withdrawing or completing this questionnaire, please contact the Carruth Center for Psychological and Psychiatric Services at (304) 293-4431. The Carruth Center is located on the 3rd floor of the Student Services Building at the Downtown campus. You will also be presented with a list of additional mental health providers located in your community at the end of the survey.

\section{Confidentiality}

Your responses are completely confidential. If you choose, you may provide your mailing address in order to be awarded $\$ 5$. Any information you provide will be maintained separately from your responses and remain confidential.

Questions About the Research 
If you have any questions or concerns about participating, or would like to receive a copy of the results, then please contact Adam Moller at amoller1@mix.wvu.edu. Additionally, you may contact the supervisor of this study, Dr. James Bartee, at James.Bartee@ mail.wvu.edu or (304) 293-2227. For questions regarding your rights as a participant, please contact Lilo Ast, Senior Program Coordinator for Research Compliance, West Virginia University, at (304) 293-7555 or Lilo.Ast@mail.wvu.edu.

Acknowledgement of Cover Letter

I have read the above information concerning the nature of the study. By checking the box below and entering my initials, I am indicating that I have read the above information and understand what my participation entails. I agree to participate in the study until I decide otherwise. 


\section{Appendix B}

\section{Cover Letter to Serve as a Participant in Research (MSU)}

You are being asked to participate in a research study by Adam Moller, M.S. who is under the supervision of Dr. James Bartee. Adam is a doctoral student and Dr. Bartee is the Training Director in the Department of Counseling, Rehabilitation Counseling, and Counseling Psychology at West Virginia University, Morgantown, WV. Adam is also a staff counselor at Counseling and Psychological Services at Montana State University, Bozeman, MT. Before you agree to participate, please read this form to ensure that you understand the purpose of this project and what your participation will involve.

\section{Purpose of the Research}

The purpose of this study is to explore the experiences of young adults who lost a parent in adolescence.

\section{Time Needed}

It will take about 15 to 20 minutes to complete the questionnaire.

\section{Voluntary Participation}

Your participation is completely voluntary, and you may withdraw at any time. Although the research will be helped if you answer all of the questions, you can skip any item that you wish not to answer. There will never be any negative consequences for non-participation or non-completion.

\section{Benefits of the Research}

There may not be any direct benefits to you from this study. However, your responses will help future young adults who have lost a parent in adolescence.

\section{Compensation for Participation}

As compensation for participating in this study, the first 20 bereaved and first 20 non-bereaved will be awarded $\$ 5$ if you provide your mailing address at the end of the survey.

\section{Procedures and Risks}

If you chose to participate in this study, you will be asked to provide demographic information and complete two questionnaires. Filling out these questionnaires may bring up upsetting thoughts or feelings. If this occurs, you may withdraw from the study at any time. If you feel the need to talk with someone after withdrawing or completing this questionnaire, please contact Counseling and Psychological Services at (406) 994-4531. Counseling and Psychological Services is located at 211 Swingle, adjacent to the Strand Union Building. You will also be presented with a list of additional mental health providers located in your community at the end of the survey.

\section{Confidentiality}

Your responses are completely confidential. If you choose, you may provide your mailing address in order to be awarded $\$ 5$. Any information you provide will be maintained separately from your responses and remain confidential. 
Questions About the Research

If you have any questions or concerns about participating, or would like to receive a copy of the results, then please contact Adam Moller at amoller1@mix.wvu.edu. Additionally, you may contact the supervisor of this study, Dr. James Bartee, at James.Bartee@ mail.wvu.edu or (304) 293-2227. For questions regarding your rights as a participant, please contact Cheryl Johnson, Institutional Review Board Administrator, Montana State University, at (406) 994-6783 or cherylj@montana.edu.

Acknowledgement of Cover Letter

I have read the above information concerning the nature of the study. By checking the box below and entering my initials, I am indicating that I have read the above information and understand what my participation entails. I agree to participate in the study until I decide otherwise. 


\section{Appendix C}

\section{Counseling Service Referral List (WVU)}

Carruth Center for Psychological and Psychiatric Services

West Virginia University

Student Services Building, 3rd Floor

Morgantown, WV 26506

(304) 293-4431

Quin Curtis Center

West Virginia University

Psychology Department, Suite 1232

Morgantown, WV 26506

(304) 293-1824

Chestnut Ridge Center

930 Chestnut Ridge Road

Morgantown, WV 26505

(304) 598-6277 
Appendix D

\section{Counseling Service Referral List (MSU)}

Counseling and Psychological Services

Montana State University

211 Swingle

Bozeman, MT 59717

(406) 994-4531

Gallatin Mental Health Center

699 Farmhouse Lane

Bozeman, MT 59715

(406) 556-6500

Human Development Clinic

1501 S. 3rd Ave.

Bozeman, MT 59717

(406) 994-4113 